\title{
La organización altitudinal de las formas kársticas del Macizo Occidental de los Picos de Europa (Montañas Cantábricas) y su interrelación con el glaciarismo Cuaternario y la morfodinámica periglaciar
}

\section{The altitudinal organization of the karst features of the Western Massif of the Picos de Europa (Cantabrian Mountains) and its interrelation with the Quaternary glaciers and the periglacial morphodynamics}

\author{
RUIZ-FERNÁNDEZ, J. ${ }^{1 *}$, GARCÍA-HERNÁNDEZ, C. ${ }^{1}$, FERNÁNDEZ \\ FERNÁNDEZ, A. ${ }^{2}$ \\ ${ }^{1}$ Departamento de Geografía, Universidad de Oviedo, Oviedo, España \\ ${ }^{2}$ Departamento de Geografía, Universidad Nacional de Educación a Distancia, Madrid, España. \\ *Contacto: ruizjesus@uniovi.es
}

https://doi.org/10.17979/cadlaxe.2019.41.0.5822 enviado: 20/10/2018 aceptado 22/07/2019

\begin{abstract}
In the highest mountains, the typologies of karstic features, as well as the intensity of karstic dissolution, vary according to the altitude (in addition to the structural factors). However, there are hardly any studies related to this issue. This paper, based in a systematic and exhaustive fieldwork that has been conducted for several years in the Western Massif of the Picos de Europa, focuses on the study of the karst of this high mountain area in the Cantabrian Mountains, examining processes and features, determining the important interrelations of the karstic landforms with the Quaternary glaciers and with the periglacial morphodynamics, establishing three stages of karstic evolution depending on morphoclima-
\end{abstract}


tic conditions (preglacial karst, glacial karst, and postglacial karst) and differentiating four karstic belts according to the altitudinal gradient: mid-mountain covered oceanic karst area, sector of glacial fronts and low glaciokarst depressions, karstic desert, and nival karst area of high mountain.

Key words: karstic evolution, karstic belts, glaciokarst, periglacial morphodynamics, Picos de Europa

\section{Resumen}

En los conjuntos montañosos con un desarrollo altitudinal importante, la tipología de las formas kársticas presentes, así como la intensidad de la disolución kárstica, varían en función de la altitud (además de los consabidos factores estructurales). Sin embargo, apenas existen estudios relativos a esta cuestión. Este trabajo, basado fundamentalmente en la realización de un trabajo de campo sistemático y exhaustivo que se ha prolongado durante varios años en el Macizo Occidental de los Picos de Europa, se centra en el estudio del modelado kárstico de este macizo cantábrico de alta montaña. En él se han identificado los procesos y formas presentes, determinando las interrelaciones del relieve kárstico con el glaciarismo cuaternario y con la morfodinámica periglaciar, estableciendo tres fases de evolución kárstica en función de la sucesión de distintas condiciones morfoclimáticas y de la consiguiente actuación de diversos agentes morfogenéticos (karst preglaciar, glaciar y postglaciar) y definiendo cuatro franjas kársticas a tenor del gradiente altitudinal: área de karst cubierto oceánico de media montaña, sector de los frentes glaciares y las cubetas glaciokársticas bajas, desierto kárstico, y área de karst nival de alta montaña.

Palabras clave: Evolución kárstica, franjas kársticas, glaciokarst, morfodinámica periglaciar, Picos de Europa 


\section{INTRODUCCIÓN}

Los estudios relacionados con las formas y los procesos de origen kárstico tienen una larga tradición en la geomorfología debido, entre otras cuestiones, a la extraordinaria información paleoambiental y morfológica que aportan y a sus características paisajísticas. Su estudio es una fuente imprescindible para establecer variaciones climáticas y medioambientales, de gran utilidad a la hora de reconstruir la evolución de una región (SWEETING, 1972).

La investigación relacionada con el karst refleja, en las últimas cinco décadas, una profunda transformación debido a la incorporación de nuevos temas de estudio a medida que avanzaban las técnicas de análisis y datación. De este modo, los trabajos desarrollados en la Península Ibérica desde finales de los años sesenta del siglo pasado y hasta finales del siglo XX, se centraron, la mayor parte de ellos, en investigaciones que tenían como objetivo principal, el análisis geomorfológico y la cartografía de las geoformas kársticas. La atención de los investigadores se centraba en los ámbitos de la montaña cantábrica-pirenaica (ej.: MIOTKE, 1968; HOYOS, 1979; LÓPEZ-MARTÍNEZ, 1984; SMART, 1984, 1986; HOYOS Y HERRERO, 1989; ROSSI, 2004; SANTOS Y MARQUÍNEZ, 2005; GONZÁLEZ-TRUEBA, 2007b; RUIZ-FERNÁNDEZ Y SERRANO, 2011) pero también en la áreas montañosas situadas en el dominio climático mediterráneo (ej.: LÓPEZ-BERMÚDEZ, 1974; ALONSO Y BULLÓN, 1976; BULLÓN, 1986; ALONSO, 1986; ALONSO et al., 1987; DELANNOY et al., 1989; DÍAZ DEL OLMO et al., 1994; DURÁN, 1996; GONZÁLEZ-AMUCHASTEGUI, 1998; DELANNOY, 1999; FERNÁNDEZ, 2000).
El cambio de siglo supuso una disminución de la producción de esta línea de trabajo, si bien se sigue investigando sobre aspectos morfológicos (PARDO-IGÚZQUIZA et al., 2016).

Por otra parte, dentro de los estudios del karst han sido múltiples los trabajos realizados sobre formaciones tobáceas en diferentes regiones y ámbitos geomorfológicos peninsulares, como la submeseta sur y sus rebordes montañosos (ej.: GONZÁLEZ et al. 1987; GONZÁLEZ-AMUCHASTEGUI y GONZÁLEZ, 1993; FERNÁNDEZ et al., 1996, 1998; GARCÍA DEL CURA et al., 1996; GONZÁLEZ et al. 2000), la cuenca del Ebro y sus contornos montañosos (ej: GRACIA Y CUCHÍ, 1993; SANCHO et al., 1997; ARENAS et al. 2000; VÁZQUEZ et al. 2011, 2013; GONZÁLEZ-AMUCHASTEGUI Y SERRANO, 2013), así como Andalucía, Baleares y Cataluña (ej.: CRUZ, 1981; BAENA, 1993; DÍAZ DEL OLMO, 1994; BRUSI et al., 1997; PORRAS, 2000; LÓPEZ, 2007; VICENS et al., 2014).

El estudio de las tobas se fue enriqueciendo al añadir perspectivas ambientales y patrimoniales, además de los estudios puramente morfocronológicos (ej: FERNÁNDEZ, 2000; GONZÁLEZ Y RUBIO, 2000; CARRASCO, 2002; CURRAS et al., 2012; GONZÁLEZ-AMUCHASTEGUI y SERRANO, 2007; GONZÁLEZ et al., 2014; FERNÁNDEZ et al., 2015).

El paisaje kárstico en un área de montaña se encuentra determinado por la altitud, pues de esta depende el volumen de precipitación, las condiciones térmicas, la posible existencia o inexistencia de cubierta edáfica y la duración y extensión de la cubierta nival, todos ellos factores que condicionan el desarrollo del karst. Si la formación tobácea precisa de unos marcos fitoclimáticos pre- 
cisos (GARCÍA-CODRÓN, 1989) y su desarrollo alcanza sus máximos en ambientes templados, húmedos y de gran regularidad pluviométrica, el karst en áreas de montaña, debido a la altitud, sigue otras pautas que aseguran su evolución de un modo casi permanente.

Los estudios sobre morfología kárstica, en los que se relacione la altitud con las formas y procesos kársticos, son casi inexistentes en áreas de montaña. Sin embargo, las condiciones topoclimáticas hacen variar dichos procesos y, por tanto, las geoformas kársticas presentes. Ello determina que se puedan establecer y diferenciar ciertas tipologías morfológicas según las bandas altitudinales. En efecto, la variación altitudinal introduce una elevada geodiversidad kárstica en las áreas de montaña, tanto en sus formas exokársticas como endokársticas (SENIOR, 1987; BALLESTEROS et al., 2011) por ello, en este sentido, el presente trabajo se centra en el estudio del modelado kárstico de un macizo cantábrico de alta montaña, el Macizo Occidental de los Picos de Europa, con los objetivos específicos de: i) identificar los procesos y formas exokársticas y endokársticas presentes; ii) determinar las interrelaciones del relieve kárstico con el glaciarismo cuaternario y con la morfodinámica periglaciar, iii) establecer las fases de la evolución kárstica y, iv) definir las franjas kársticas que se diferencian en dicho ámbito a tenor del gradiente altitudinal.

\section{II. ÁREA DE ESTUDIO}

El Macizo Occidental de los Picos de Europa, también llamado Macizo del Cornión, culmina en la cima de Peña Santa de Castilla (2596 m), siendo el segundo en altitud de los tres que integran los Picos de Europa (Figu- ra 1). Al igual que los otros dos, el Cornión está integrado básicamente por calizas de edad carbonífera, organizadas en una serie de escamas cabalgantes verticalizadas y apiladas unas sobre otras siguiendo un rumbo aproximado E-W, que en algunos sectores superan ampliamente los $2000 \mathrm{~m}$ de potencia (MARQUÍNEZ, 1978, 1989; FARIAS, 1982). Este macizo calcáreo ha sido intensamente transformado por la karstificación y los glaciares cuaternarios (CASTAÑóN, 1989; FROCHOSO Y CASTAÑÓN, 1998; GONZÁLEZ-TRUEBA， 2007a， 2007b; SERRANO et al., 2013; RUIZ-FERNÁNDEZ, 2015; RUIZ-FERNÁNDEZ et al., 2016; RUIZ-FERNÁNDEZ Y GARCÍAHERNÁNDEZ, 2018), y retocado por la dinámica periglaciar relicta y actual (CASTAÑÓN Y FROCHOSO, 1994, 1998; SERRANO Y GONZÁLEZ-TRUEBA, 2004; GONZÁLEZ-TRUEBA， 2007a; RUIZFERNÁNDEZ et al., 2014; 2016; 2017). Desde el punto de vista climático, la alta montaña de los Picos de Europa está definida actualmente por precipitaciones muy abundantes, superiores a los $2000 \mathrm{~mm} / \mathrm{año} \mathrm{y}$ en gran parte en forma de nieve, así como por temperaturas bajas. MUÑOZ (1982) sitúa la isoterma anual de $0^{\circ} \mathrm{C}$ en la región entre 2400 y $2500 \mathrm{~m}$ de altitud. Este mismo autor señala que en los Picos de Europa se registran unos 85 días anuales de precipitaciones nivales, que representarían el 70\% del volumen pluviométrico total. Según la clasificación de Köppen, la alta montaña de los Picos de Europa se define por un clima de tipo Dfsc (MUÑOZ, 1982). La vegetación presente es de tipo Eurosiberiano, destacando la existencia de diversos bosques de frondosas planocaducifolias entre los que destacan los hayedos. El límite superior del bosque se encuentra en torno a 1400 m s.n.m., rebajado 
por la secular acción humana. Por encima de esta cota se desarrollan diversas formaciones arbustivas y herbáceas que, con el aumento de la altitud, van ocupando progresivamente menor superficie. Salvo la existencia de asentamientos estacionales relacionados con el pastoreo, los núcleos de población quedan circunscritos a la periferia del macizo. Además de la ganadería, en la actualidad las actividades humanas en este espacio están relacionadas con el turismo, la espeleología y los deportes de montaña.

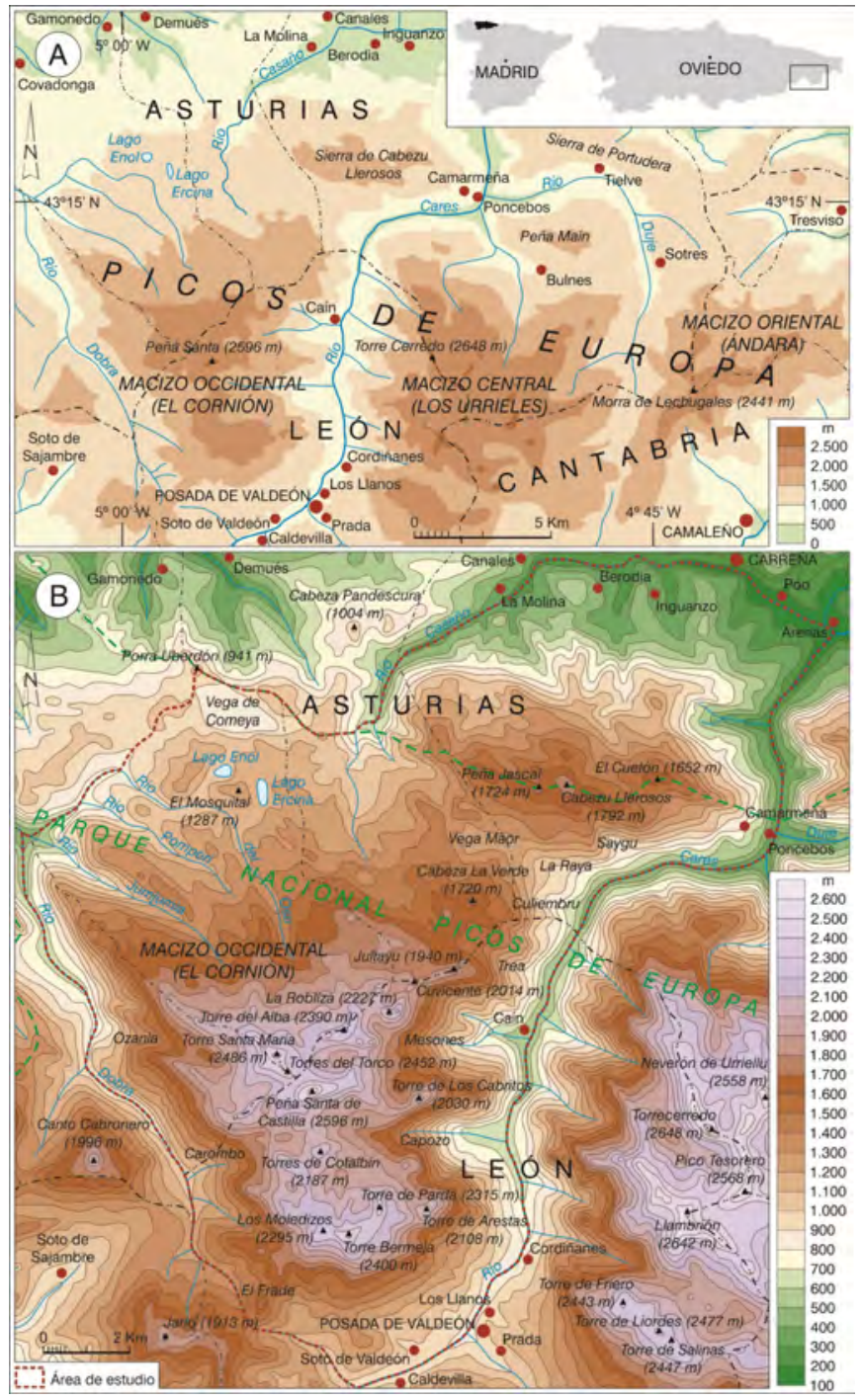

Fig. 1. Mapa de localización general de los Picos de Europa (A), y detalle del macizo Occidental con la delimitación del área de estudio (B). 


\section{METODOLOGÍA}

Este estudio se fundamenta en la realización de recorridos sistemáticos por el Macizo del Cornión, efectuados durante los veranos de 2005 a 2011, a fin de determinar las formas y procesos kársticos existentes, así como su distribución espacial y altitudinal y su relación con otros procesos y formas de modelado, como los de origen glaciar, periglaciar y nival. La terminología usada, especialmente la relacionada con los tipos de lapiaz, es la usada habitualmente en las obras de referencia sobre el karst (ej.: NICOD, 1972; SWEETING, 1972; WHITE, 1988; FORD Y WILLIAMS, 1989). En el caso concreto de las principales cubetas glaciokársticas del Macizo del Cornión (a escala cartográfica), se ha efectuado un análisis morfométrico básico, sintetizado en la Tabla 1. En concreto, se ha calculado el perímetro de cada depresión $\left(A_{\max }\right)$, la altitud de su fondo $\left(A_{\min }\right)$, el desnivel o diferencia entre $A_{\text {max }}$ y $A_{\text {min }}(D)$, la longitud máxima $(L)$, la anchura máxima $(A)$ y el área $(A r)$.

Con respecto a la toponimia, conviene aclarar que se ha utilizado la grafía "H.", que es la empleada en lengua asturiana para representar la aspiración de la h, característica en el oriente de Asturias y en toda el área de los Picos de Europa, incluyendo sus sectores cántabro y leonés. Si bien, la castellanización de este fonema, ha dado lugar a la utilización frecuente e incorrecta de la " $\mathrm{H}$ ", por ejemplo en el caso de los h.oyos (hoyos), o la "J" (el fonema más similar a la $\mathrm{h}$ aspirada), como grafía empleada en cartografía y documentación científica para referirse a h.ous (jous) y h.oos (joos), término con el que, en este área, se denomina a las depresiones kársticas y glaciokársticas, independientemente de su tamaño.

\section{RESULTADOS}

\section{El modelado kárstico del Macizo Occiden- tal de los Picos de Europa}

El modelado kárstico del Cornión, que constituye un holokarst (CVIJIC, 1893), es decir, un ámbito en el que prima la constante infiltración de las escorrentías hacia el interior de la roca caliza, impidiendo el desarrollo de la escorrentía superficial (salvo en el caso de unos pocos cauces menores situados en los bordes del macizo), se caracteriza por una gran riqueza de formas de diversas escalas, tanto exokársticas como endokársticas, y tanto generadas por la disolución kárstica como debidas a la precipitación de los carbonatos, que se describen a continuación:

\subsection{Formas exokársticas mayores}

En el Cornión existe únicamente un poljé, la Vega de Comeya, situado en el entorno de los lagos Enol y Ercina, con una extensión de 1,2 km² y un desnivel de casi $200 \mathrm{~m}$ entre su fondo y la culminación del escape meridional que lo delimita (Figura 2). En planta, el poljé adquiere una forma triangular, con casi $2 \mathrm{~km}$ de longitud y $\sim 800 \mathrm{~m}$ de anchura máxima. El roquedo que lo integra está afectado por una red de fallas alpinas (FARIAS et al., 1996). La depresión está recubierta de sedimentos torrenciales, lacustres y turbosos, así como debidos a avalanchas rocosas y deslizamientos. Este relleno ha generado una superficie plana por la que circula una red fluvial meandriforme que se sume en un ponor situado en la terminación NW de la depresión.

Las cubetas glaciokársticas son formas del relieve ampliamente representadas en el Cornión. Se trata de depresiones generadas 


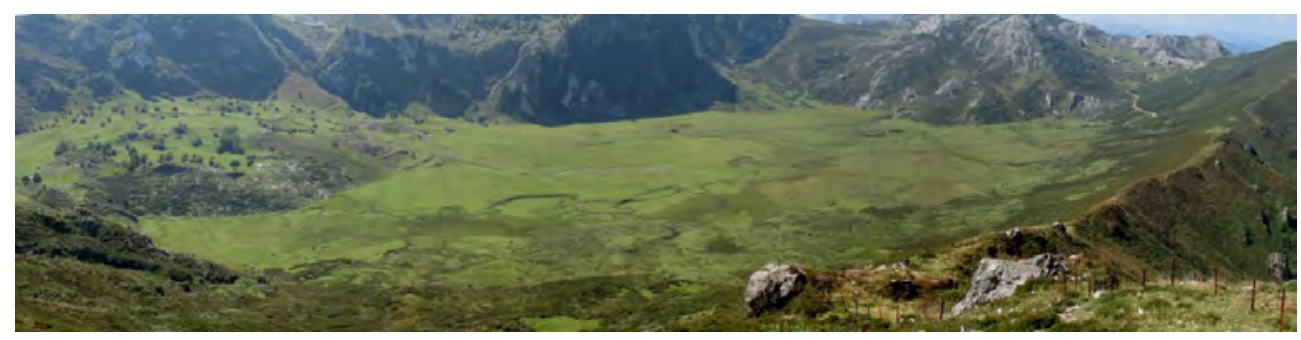

Fig. 2. Vista general de la Vega de Comeya desde su borde nororiental.

por la karstificación que, posteriormente, han sido retrabajadas por el hielo glaciar (MIOTKE, 1968). Estas macroformas se distribuyen mayoritariamente a lo largo de las principales líneas de fracturación local, de rumbo aproximado NW-SE, y sus morfologías resultantes están nítidamente guiadas por el dispositivo estructural (Figura 3).

$\mathrm{Su}$ superficie media es de 11,3 ha y su profundidad media es de $28 \mathrm{~m}$ (Tabla 1). Sus dimensiones oscilan desde las de grandes hoyas con longitudes próximas a $1 \mathrm{~km}$ (H.ou Luengo, H.oyos del Caballo, Vega de
Aliseda) e incluso superiores (H.ou Santo), a pequeñas cubetas de apenas 100-200 m de diámetro que se encuentran tanto exentas como inscritas dentro de otras de mayor tamaño; y superficies comprendidas entre las 58 ha de la cubeta más extensa a las 1-2 ha que alcanzan numerosas depresiones de este tipo. Lo mismo ocurre con la profundidad (diferencia entre la altitud mínima del perímetro de cada depresión y la del fondo), que oscila entre los $105 \mathrm{~m}$ del H.ou Santo y desniveles inferiores a $20 \mathrm{~m}$, como acontece en los H.oos de Resecu (Tabla 1). 

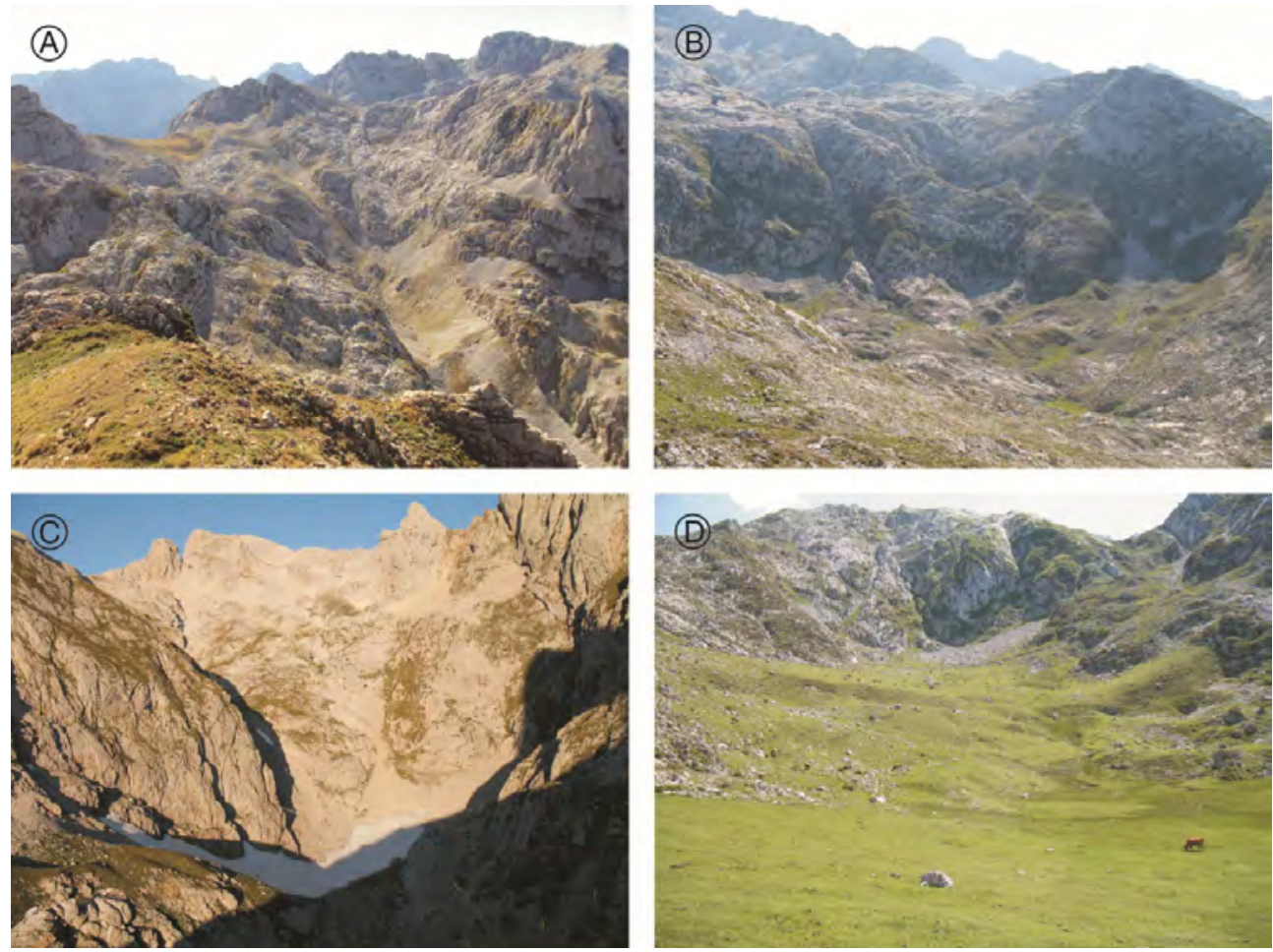

Fig. 3. Influencia del dispositivo estructural en la morfología de las cubetas glaciokársticas. La depresión de la Duernona (A), con la Torre Bermeja al fondo $(2400 \mathrm{~m})$, adquiere una disposición alargada debido a la existencia de dos grandes fallas paralelas de rumbo ESE-WNW, visibles en la imagen. Asimismo, se percibe nítidamente la influencia de varias fracturas, algunas de ellas entrecruzadas, en la morfología de las cubetas glaciokársticas de los H.oos de Resecu (B), el H.oón de Oliseda (C) y la Vega de Justillagar (D).

Habitualmente adquieren formas ovaladas en planta (H.ou Santo, H.oón de Oliseda, la Duernona, H.ou del Requexón, Vega de Ario, Vega de las Bobias, Vega del Ceñal, Vega de Justillagar, etc.), aproximadamente circulares (H.ou del Agua, H.ou de la Canal Parda, H.ou las Pozas, H.oos de Huerta, H.ou Piedras Luengas, H.oos de Resecu, etc.), e incluso también estrelladas (H.ou Sin Tierri, H.ou de los Asturianos) (Tabla 1). Por otro lado, en perfil las cubetas glaciokársticas pueden tener vertientes tendidas, suaves, y un escaso desnivel altimétrico, o por el contrario bordes escarpados, subverticales, dando lugar en este último caso a depresiones profundas, por lo que es frecuente que su fondo se encuentre tapizado en mayor o menor medida por depósitos de ladera.

El H.ou Santo (entre el Collado Santo y el Boquete) es la depresión glaciokárstica más extensa del macizo, con 58 ha. A continuación destacan los H.oyos del Caballo con 38,4 ha, el otro sector del H.ou Santo (entre el H.ou de los Asturianos y las inmediaciones de la Forcadona) con 37,5 ha, el 
H.ou las Pozas con 22 ha y el H.ou Julagua con 21,6 ha. Seguidamente hay otra serie de depresiones con áreas comprendidas entre 20 y 10 ha como el H.ou Luengo, la Vega el Paré, los Llanos del Sordo, la Duernona y la Vega de las Bobias. Finalmente, hay un nutrido grupo de depresiones con menos de 10 ha de extensión, entre las que cabe destacar los H.oos de Huerta, el H.ou la Fuente, el H.ou Sin Tierri, la Vega de la Llastria o el H.ou de la Canal Parda (Tabla 1).

\begin{tabular}{|c|c|c|c|c|c|c|c|}
\hline Cubeta & $A_{\max }(\mathrm{m})$ & $A_{\min }(\mathrm{m})$ & $D(\mathrm{~m})$ & $L(\mathrm{~m})$ & $A(\mathrm{~m})$ & $A r$ (ha) & Morfología \\
\hline H.ou Santo 1 & 2012 & 2907 & 105 & 1450 & 500 & 58 & Ovalada \\
\hline H.oyos del Caballo 1 & 1930 & 1863 & 67 & 960 & 500 & 38,4 & Ovalada \\
\hline H.ou Santo 2 & 2091 & 2015 & 76 & 750 & 625 & 37,5 & Ovalada \\
\hline H.ou las Pozas & 2010 & 1972 & 38 & 550 & 500 & 22 & Circular \\
\hline H.ou Julagua & 1475 & 1434 & 41 & 600 & 450 & 21,6 & Triangular \\
\hline H.ou Luengo & 1725 & 1656 & 69 & 1000 & 250 & 20 & Ovalada \\
\hline Vega el Paré & 1360 & 1352 & 8 & 675 & 350 & 18,9 & Ovalada \\
\hline Llanos del Sordo & 1410 & 1367 & 43 & 625 & 375 & 18,7 & Ovalada \\
\hline Lago Enol & 1076 & 1052 & 24 & 550 & 400 & 17,6 & Ovalada \\
\hline Vega de las Bobias & 1244 & 1227 & 17 & 625 & 350 & 17,5 & Ovalada \\
\hline H.oyos del Caballo 2 & 1870 & 1836 & 34 & 850 & 250 & 17 & Ovalada \\
\hline H.oyos Llerosos & 2126 & 2111 & 15 & 700 & 300 & 16,8 & Ovalada \\
\hline Vega de Aliseda & 1793 & 1749 & 44 & 875 & 225 & 15,7 & Ovalada \\
\hline Vega de Ario & 1615 & 1592 & 23 & 550 & 350 & 15,4 & Ovalada \\
\hline Vega del Ceñal & 1386 & 1341 & 45 & 750 & 250 & 15 & Ovalada \\
\hline H.oyo de Argüelles & 2010 & 1970 & 40 & 625 & 300 & 15 & Ovalada \\
\hline H.ou la Cistra & 1575 & 1528 & 47 & 525 & 350 & 14,7 & Ovalada \\
\hline H.oyos Cavaos 1 & 2000 & 1991 & 9 & 600 & 300 & 14,4 & Ovalada \\
\hline Los Pozos & 1405 & 1354 & 51 & 800 & 225 & 14,4 & Ovalada \\
\hline Lago Ercina & 1115 & 1100 & 15 & 700 & 250 & 14 & Ovalada \\
\hline Vega del Bricial & 1125 & 1103 & 22 & 500 & 350 & 14 & Ovalada \\
\hline Jascal & 1454 & 1431 & 23 & 1000 & 175 & 14 & Ovalada \\
\hline H.ou de los Asturianos & 2091 & 2042 & 49 & 425 & 375 & 12,7 & Estrellada \\
\hline Moandi & 1455 & 1437 & 18 & 625 & 250 & 12,5 & Ovalada \\
\hline H.oyo Verde & 1643 & 1597 & 46 & 500 & 300 & 12 & Ovalada \\
\hline La Duernona & 1805 & 1770 & 35 & 750 & 200 & 12 & Ovalada \\
\hline Joos de Resecu & 1490 & 1475 & 15 & 375 & 375 & 11,2 & Circular \\
\hline H.ou la Canal & 1453 & 1419 & 34 & 425 & 325 & 11 & Ovalada \\
\hline Joos de Huerta & 1690 & 1662 & 28 & 425 & 400 & 9,75 & Circular \\
\hline
\end{tabular}




\begin{tabular}{|l|c|c|c|c|c|c|c|}
\hline Los Reguerones & 1015 & 1015 & 0 & 475 & 250 & 9,5 & Ovalada \\
\hline Vega de Justillagar & 1468 & 1419 & 49 & 500 & 225 & 9 & Ovalada \\
\hline H.ous de Peña Blanca & 1865 & 1830 & 35 & 400 & 275 & 8,8 & Ovalada \\
\hline Joón de los Desvíos & 1905 & 1870 & 35 & 375 & 275 & 8,2 & Ovalada \\
\hline Garapozales & 1916 & 1902 & 14 & 375 & 275 & 8,2 & Ovalada \\
\hline H.ou la Fuente & 1325 & 1315 & 10 & 375 & 275 & 8,2 & Ovalada \\
\hline H.oyos Cavaos 2 & 2005 & 1990 & 15 & 500 & 200 & 8 & Ovalada \\
\hline Arnaedo & 1279 & 1260 & 19 & 400 & 250 & 8 & Ovalada \\
\hline H.ou Sin Tierri & 1782 & 1763 & 19 & 325 & 300 & 7,8 & Estrellada \\
\hline H.ou de los Llagos & 1455 & 1425 & 30 & 300 & 300 & 7,2 & Circular \\
\hline Brañarredonda & 1019 & 1014 & 5 & 450 & 200 & 7,2 & Ovalada \\
\hline H.ou de Cueva Andria & 1485 & 1452 & 33 & 300 & 300 & 7,2 & Circular \\
\hline La Vallugada & 1940 & 1926 & 14 & 425 & 200 & 6,8 & Ovalada \\
\hline Vega la Llastria & 1748 & 1724 & 24 & 375 & 225 & 6,7 & Ovalada \\
\hline Las Grayeras & 1405 & 1393 & 12 & 300 & 275 & 6,6 & Circular \\
\hline H.ou de Teyeres & 1442 & 1424 & 18 & 350 & 225 & 6,3 & Ovalada \\
\hline La Güelga & 1038 & 1038 & 0 & 375 & 200 & 6 & Ovalada \\
\hline Joón de Oliseda & 1814 & 1780 & 34 & 425 & 175 & 5,9 & Ovalada \\
\hline H.ou Piedras Luengas & 1900 & 1876 & 24 & 250 & 250 & 5 & Circular \\
\hline Cuestas H.ou Sin Tierri & 2044 & 2024 & 20 & 275 & 225 & 4,9 & Ovalada \\
\hline H.ous de Horcada & 1960 & 1940 & 20 & 350 & 175 & 4,9 & Ovalada \\
\hline H.ou del Agua & 1683 & 1660 & 23 & 275 & 225 & 4,9 & Circular \\
\hline El Canalizo & 1295 & 1285 & 10 & 250 & 225 & 4,5 & Circular \\
\hline H.ou de la Canal Parda & 2205 & 2172 & 45 & 250 & 175 & 3,5 & Circular \\
\hline
\end{tabular}

Tabla 1. Morfología y características morfométricas de las principales cubetas glaciokársticas del Macizo del Cornión ordenadas de acuerdo con la superficie que ocupan. Altitud mínima del perímetro de la depresión $\left(A_{\max }\right)$, altitud del fondo de la depresión $\left(A_{\min }\right)$, desnivel o diferencia entre $A_{\max }$ y $A_{\min }(D)$, longitud máxima $(L)$, anchura máxima $(A)$, área $(A r)$.

Es frecuente que se desarrollen depresiones de escasa entidad en el propio interior de las cubetas glaciokársticas. Estas depresiones internas, cuyo origen suele ser postglaciar, captan las escorrentías, constituyendo sumideros por los que las aguas superficiales penetran en la masa calcárea. Tanto las vertientes como el fondo de las cubetas situadas a mayor altitud (por ejemplo el H.ou Santo, H.ou las Pozas, H.ou de los Asturianos,
H.oyos Llerosos, H.oyos Cabaos, H.oyos del Caballo y H.oyo Tras el Horcado) suelen aparecer tapizados por depósitos conformados por material morrénico o derrubios (Figura 4); mientras que los fondos de las cubetas situadas a media y baja altitud suelen aparecer cubiertas por depósitos morrénicos (siendo las morfologías más frecuentes cordones, arcos y sobre todo mantos morrénicos), o son surcados por cursos de agua más 
bien cortos que generan turberas y áreas encharcadas para volver a infiltrarse a través de sumideros, tal como ocurre en las vegas

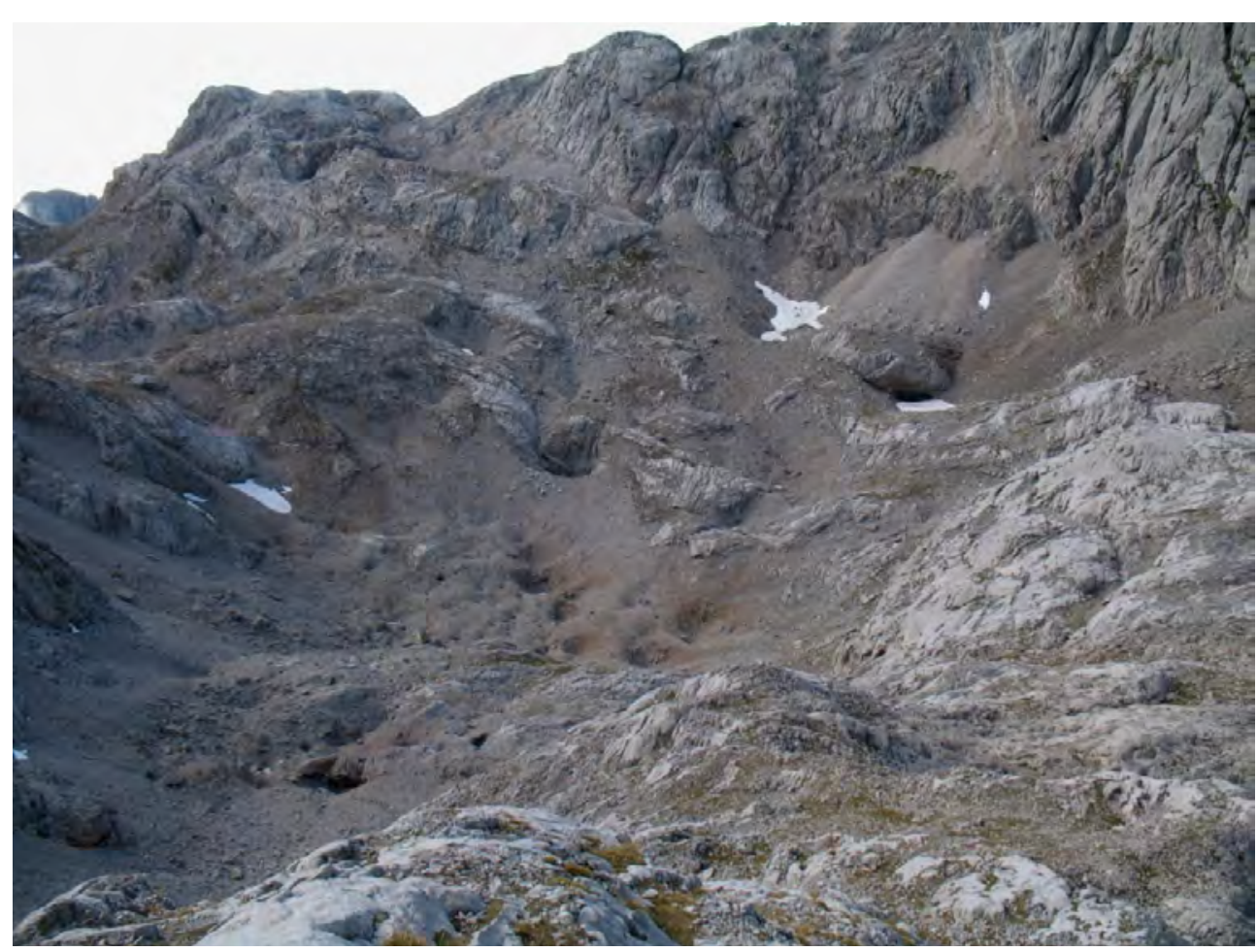

Fig. 4. Cubeta glaciokárstica del H.ou las Pozas. Obsérvese su fondo tapizado de derrubios y pequeñas depresiones de origen postglaciar (boches) que retocan la morfología de la depresión. de Justillagar, el Bricial, Ario, las Bobias, el Paré y el Ceñal (Figura 5). 


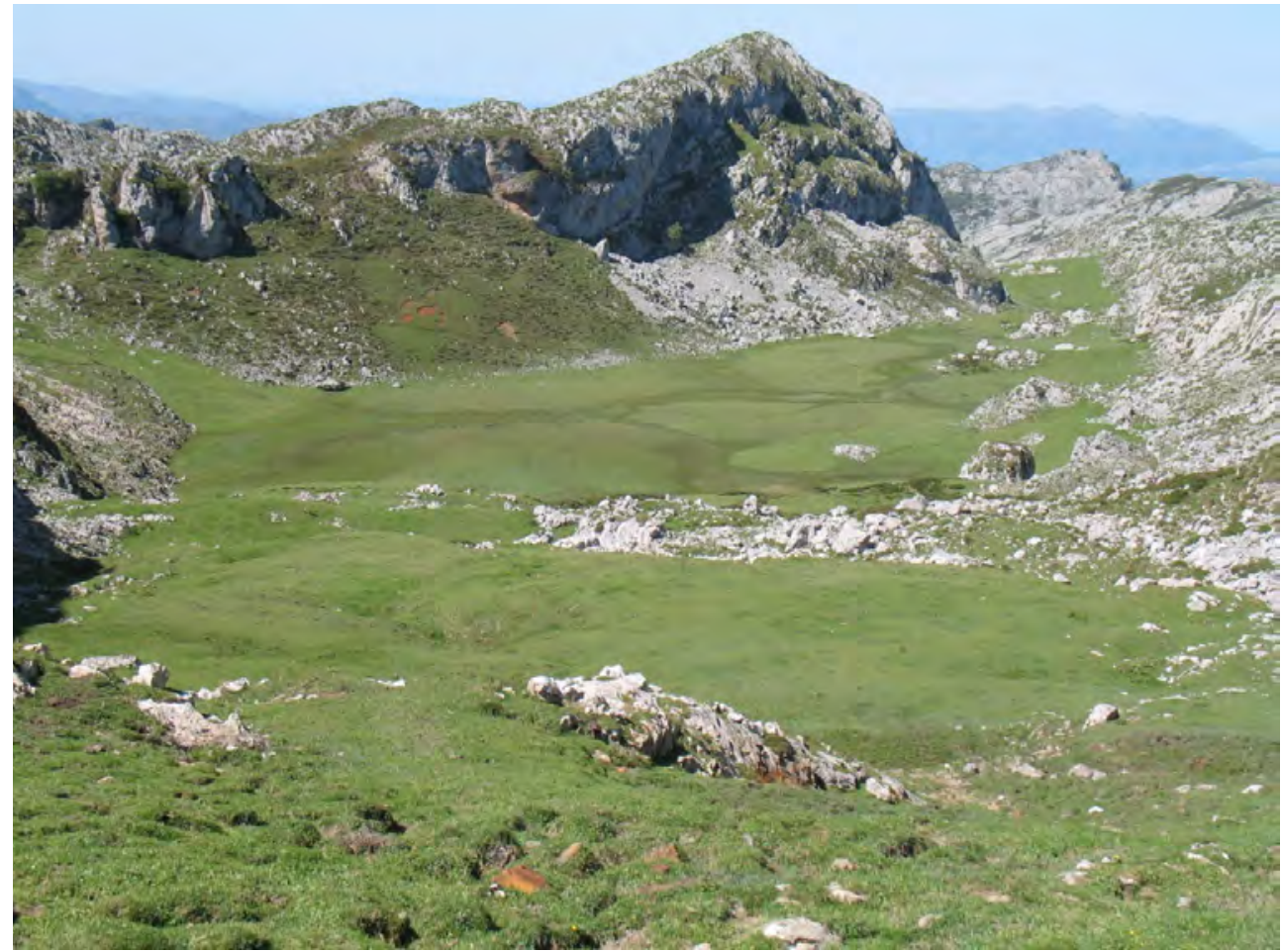

Fig. 5. Depresión glaciokárstica de la Vega el Paré. El fondo de la misma, surcado por varios arroyos que provienen de surgencias y describen pequeños meandros, se halla parcialmente encharcado, dando lugar a una turbera.

\subsection{Mesoformas kársticas}

Las dolinas, a las que en Picos de Europa se suele denominar h.ous, abundan en el Cornión, donde cuentan con gran variedad tipológica. Fuera del ámbito glaciado durante la Última Glaciación y al margen de la intensa innivación a la que están sometidos los sectores más elevados, son frecuentes las dolinas de tamaño variable, pudiendo observarse dolinas de solo unos metros de diámetro y no mucha profundidad, así como depresiones que alcanzan profundidades de 20 a $30 \mathrm{~m}$ y diámetros de $500 \mathrm{~m}$ en su eje mayor (por ejemplo en la Vega de Teón, o en la Vega las Traviesas). En las áreas periféricas del macizo aparecen dolinas en platillo que cuentan con escaso diámetro (5-10 m) y desnivel $(0,5-2 \mathrm{~m})$, bordes levemente inclinados y fondo plano, tapizadas por depósitos arcillosos de tonos rojizos. Son asimismo frecuentes las dolinas en pozo y en embudo (de gran desarrollo vertical y escaso diámetro), y en artesa (con paredes menos verticalizadas, mayor diámetro y fondo recubierto por arcillas de descalcificación). Igualmente, aparecen las dolinas de mayores dimensiones (10-50 m de eje mayor y 5-20 $\mathrm{m}$ de profundidad) denominadas dolinas en cubeta, con característicos contornos suaves 
y vertientes y fondo tapizados por terra ros$s a$. En estos sectores de media y baja altitud, como la Sierra de Covadonga, también son frecuentes las uvalas.

Por encima de $1700 \mathrm{~m}$, en los sectores de mayor altitud del Cornión, son abundantes las depresiones redondeadas en planta, de escaso diámetro, cierta profundidad y paredes rocosas verticales o en embudo, conocidas como dolinas nivales o pozos nivokársticos (Figura 6). Se distribuyen sobre la superficie de circos glaciares, umbrales y cubetas glaciokársticas, modificando y retocando su topografía superficial, constituyendo morfologías postglaciares plenamente activas. Frecuentemente, estas depresiones se agrupan formando campos que pueden alcanzar gran extensión. La protección que brindan sus paredes frente a la insolación directa, permite que en el interior de los pozos nivokársticos los neveros se conserven un tiempo tras la fusión de la mayor parte del manto nival, llegando a ser permanentes o semipermanentes en las áreas más elevadas. En los pozos nivokársticos aflora mayoritariamente la roca in situ, a diferencia de lo que ocurre en las dolinas situadas en áreas de menor altitud, que frecuentemente aparecen cubiertas o semicubiertas por formaciones superficiales (especialmente arcillas). En combinación con las acciones erosivas de origen mecánico, como la crioclastia, en estas dolinas nivales se da una intensa disolución kárstica, fruto de la circulación siguiendo ciclos diarios de las aguas de fusión, especialmente agresivas sobre la roca caliza.

Los boches o dolinas de recubrimiento (Figura 7), de escaso diámetro (1-3 m), se desarrollan sobre diferentes tipologías de sedimentos (canchales, material morrénico, arcillas de descalcificación, rellenos de tipo torrencial, fluviolacustre), como consecuencia de la disolución o el colapso del roquedo calcáreo subyacente. Se trata de formas que aparecen habitualmente en el fondo de las cubetas glaciokársticas, tal es el caso del H.ou Santo, H.ou las Pozas y H.oyo Verde, entre otras. Especialmente en las áreas más elevadas del macizo, en las que domina la infiltración de las escorrentías, son abundantes las simas, oquedades de gran desarrollo vertical y pequeño diámetro que conectan la superficie rocosa con el endokarst (Figura 8). 


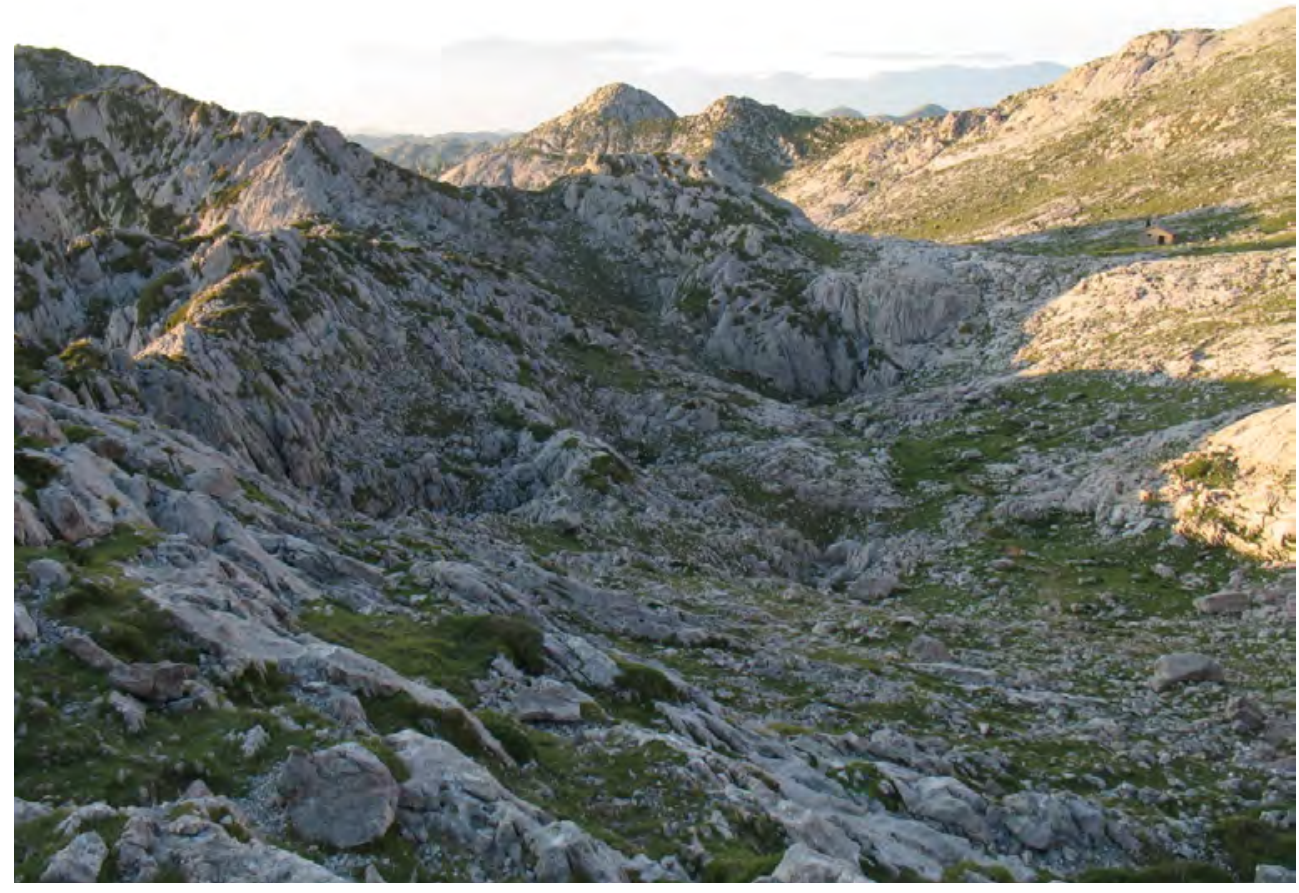

Fig. 6. Pozos nivokársticos en Ordiales.

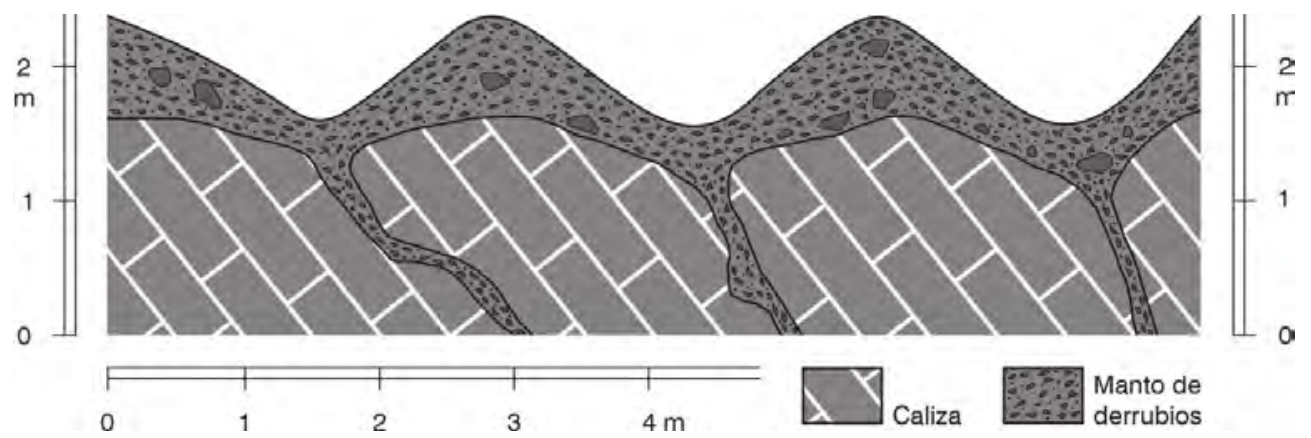

Fig. 7. Perfil geomorfológico en el que se representa la estructura y la organización interna de los boches. 


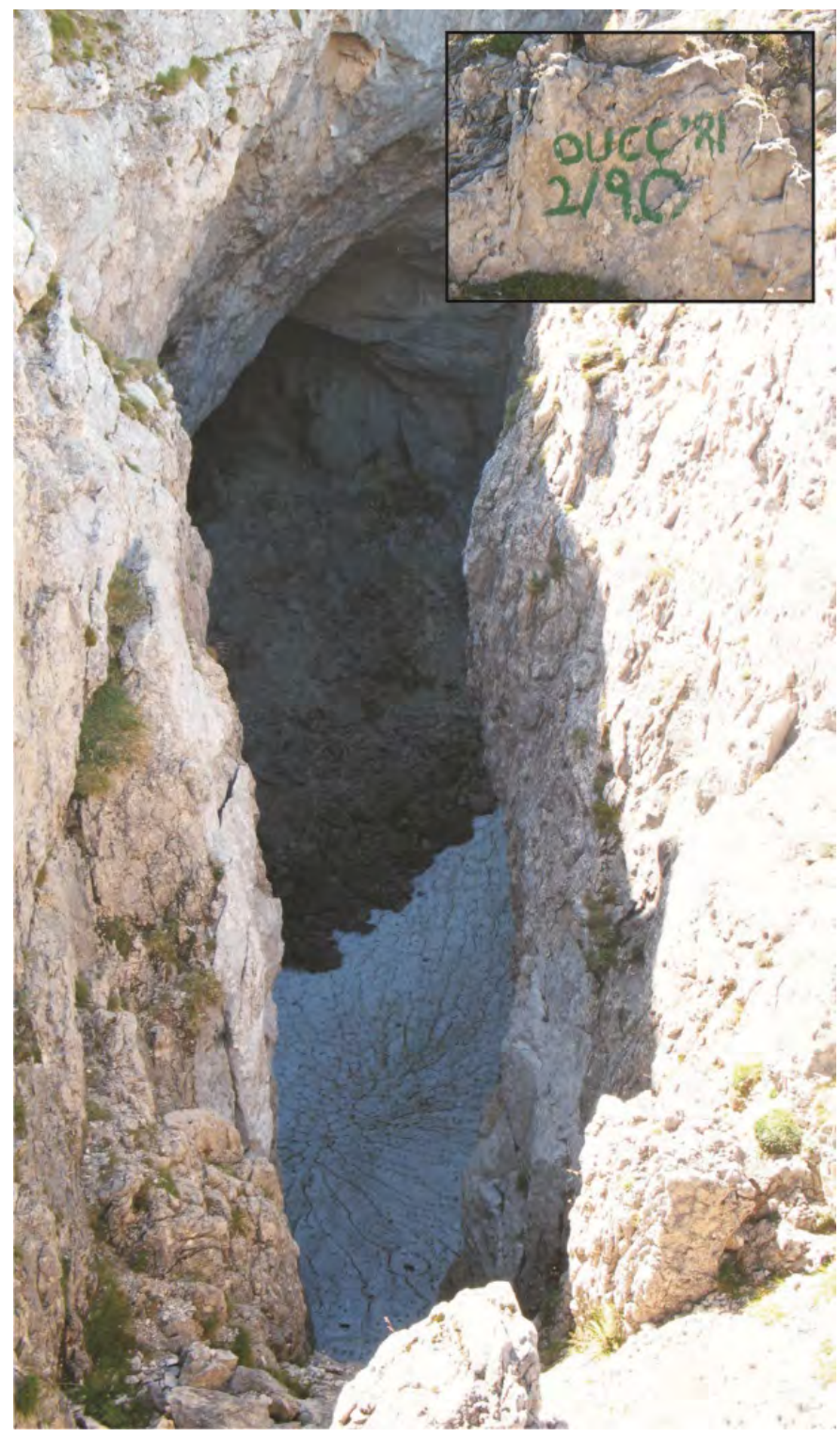

Fig. 8. Ejemplo de sima con nevero en su interior. Se trata de la sima de la H.ayada, explorada por el Oxford University Cave Club. 


\subsection{Formas exokársticas menores}

En cuanto a las formas exokársticas menores, los bogaces son frecuentes en el macizo, especialmente sobre los umbrales y superficies rocosas en resalte (Figura 9). Se trata de corredores de disolución de anchura y profundidad métrica y longitud métricas a decamétrica. Por otra parte los lapiaces, que ocupan grandes extensiones y cuentan con una variada tipología, son las morfologías menores más representativas del Cornión (Figura 10). Concretamente, son muy abundantes los lapiaces estructurales, que pueden deberse tanto a diferencias en la composición mineralógica de la roca (Figura 11), como a la presencia de líneas de debilidad en torno a las que se concentra la erosión kárstica (SANTOS Y MARQUÍNEZ, 2005), tal es el caso de los lapiaces estruturales del tipo splitkarren y kluftkarren (Figura 12).
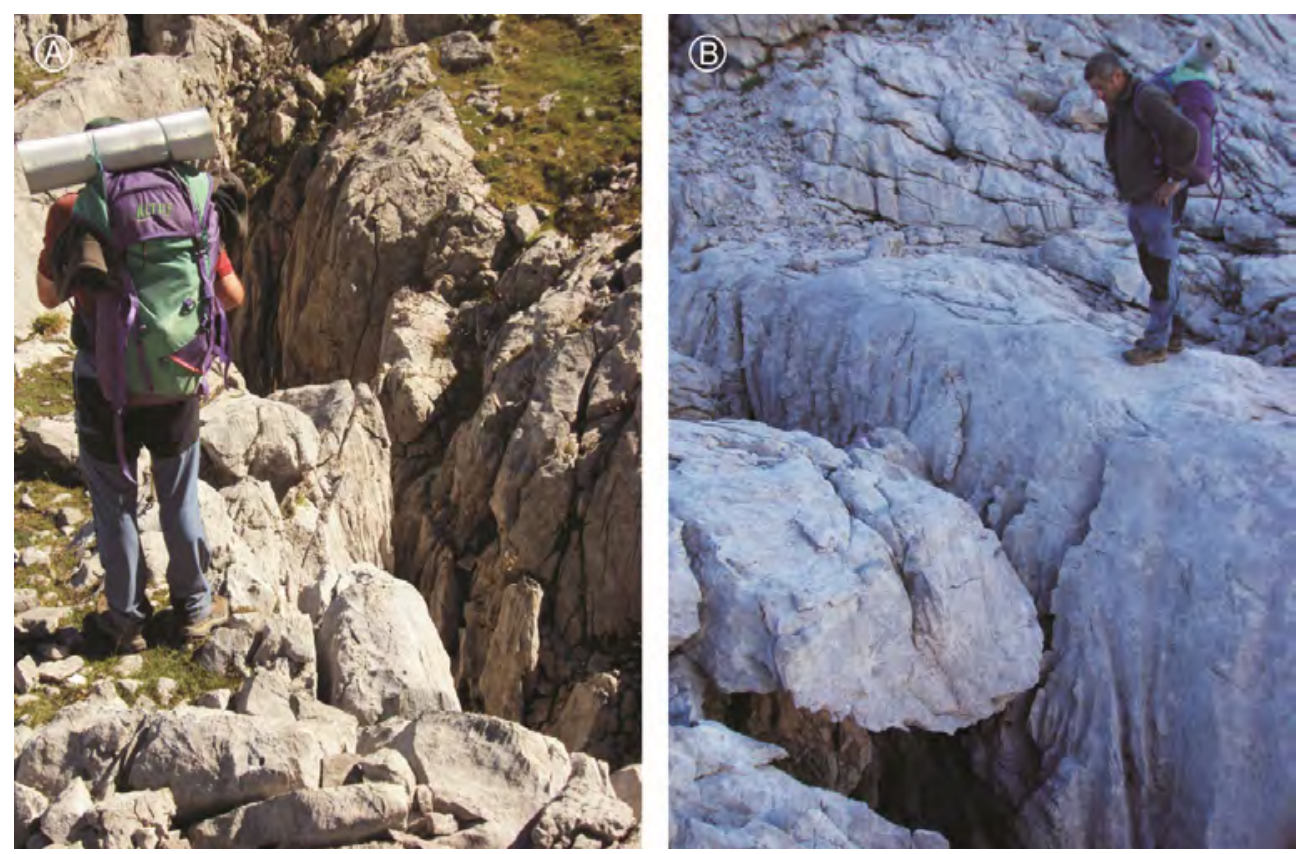

Fig. 9. Ejemplos de bogaces en el Macizo del Cornión (A y B). 


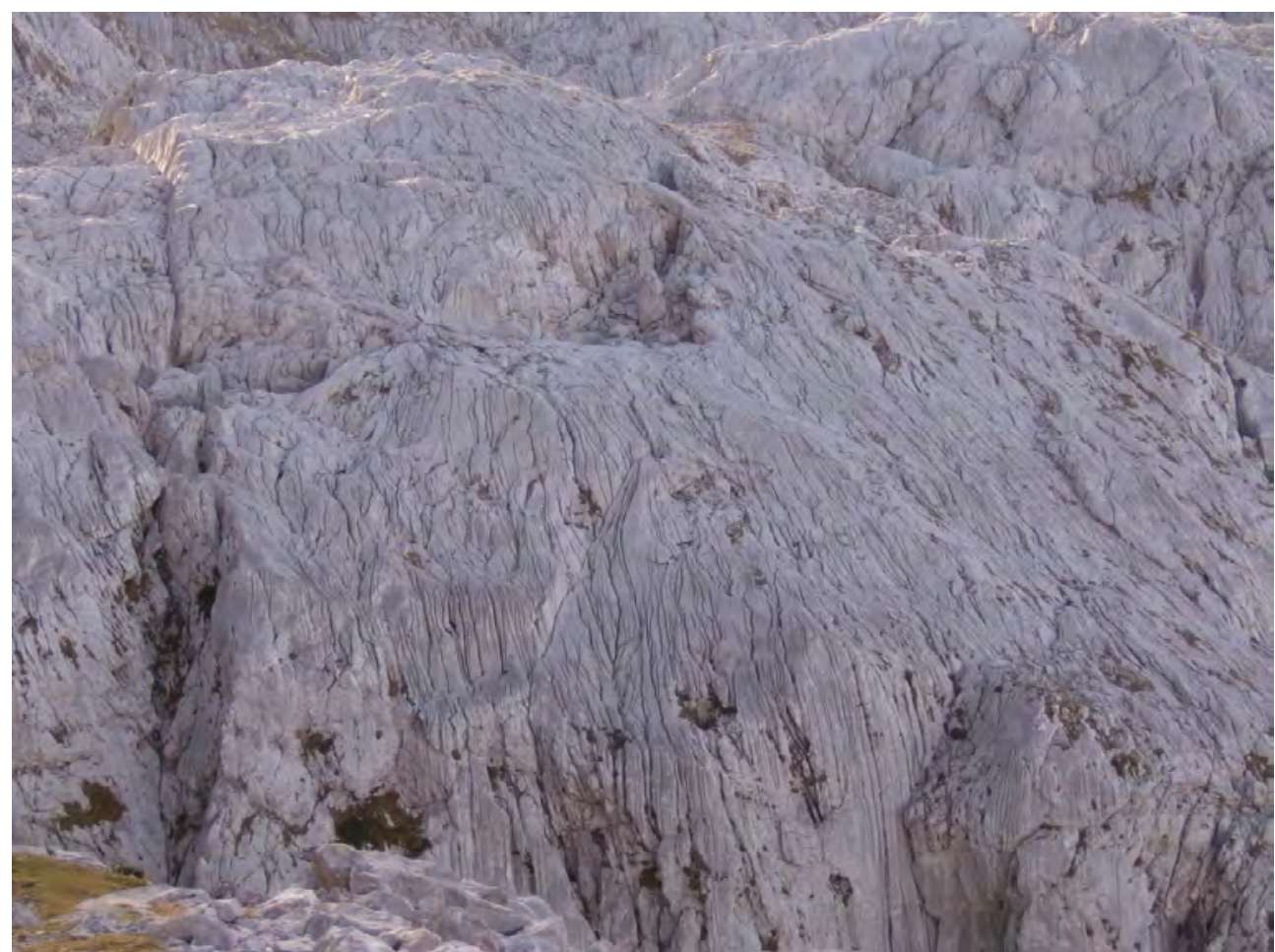

Fig. 10. Lapiaces en surcos agudos (rillenkarren), regueros (rinnenkarren) y fisurales (splitkarren y kluftkarren) en un umbral glaciar labrado sobre "calizas de Montaña" y ubicado en el área de la Llampa Cimera (bifurcación de los caminos hacia el H.ou Santo o hacia Fuente Prieta y Vega Huerta). 

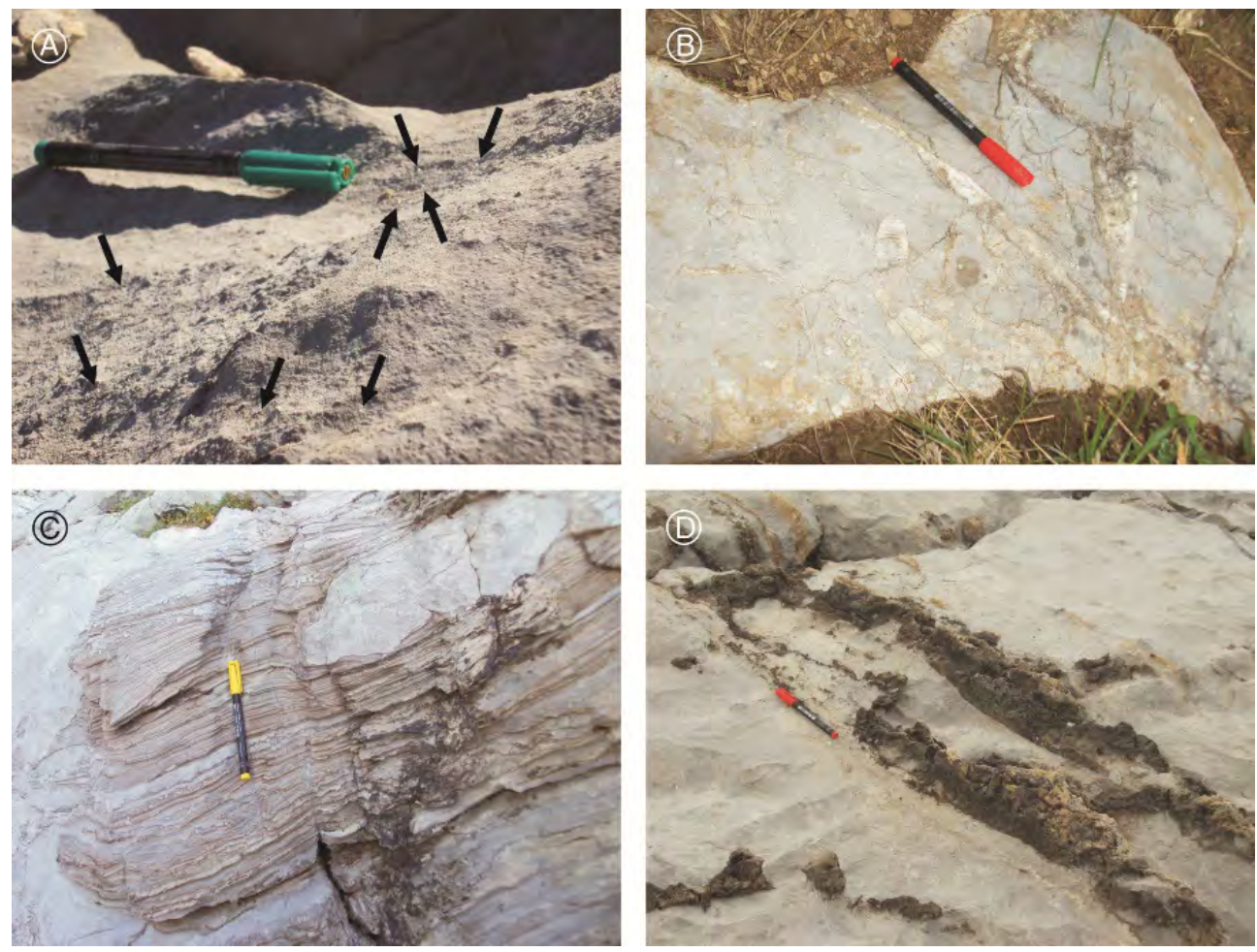

Fig. 11. Diferentes tipos de lapiaces debidos a discontinuidades mineralógicas. Afloramiento de "calizas de Picos de Europa" en el que se pueden identificar numerosos cristales idiomórficos de cuarzo de tamaños milimétricos (A), lo que hace que en detalle su superficie sea extremadamente rugosa (las Barrastrosas); venas de cuarzo y restos fósiles (son muy abundantes los restos de crinoideos) sobresaliendo por encima de la matriz calcárea de un afloramiento de "calizas de Picos de Europa" en las cercanías de Camplengu (B); laminaciones de chert sobre "calizas de Picos de Europa" en los alrededores de la Cemba Vieya (C); relieves positivos derivados de la dolomitización de las "calizas de Picos de Europa" en el área de la Cemba Vieya (D). 


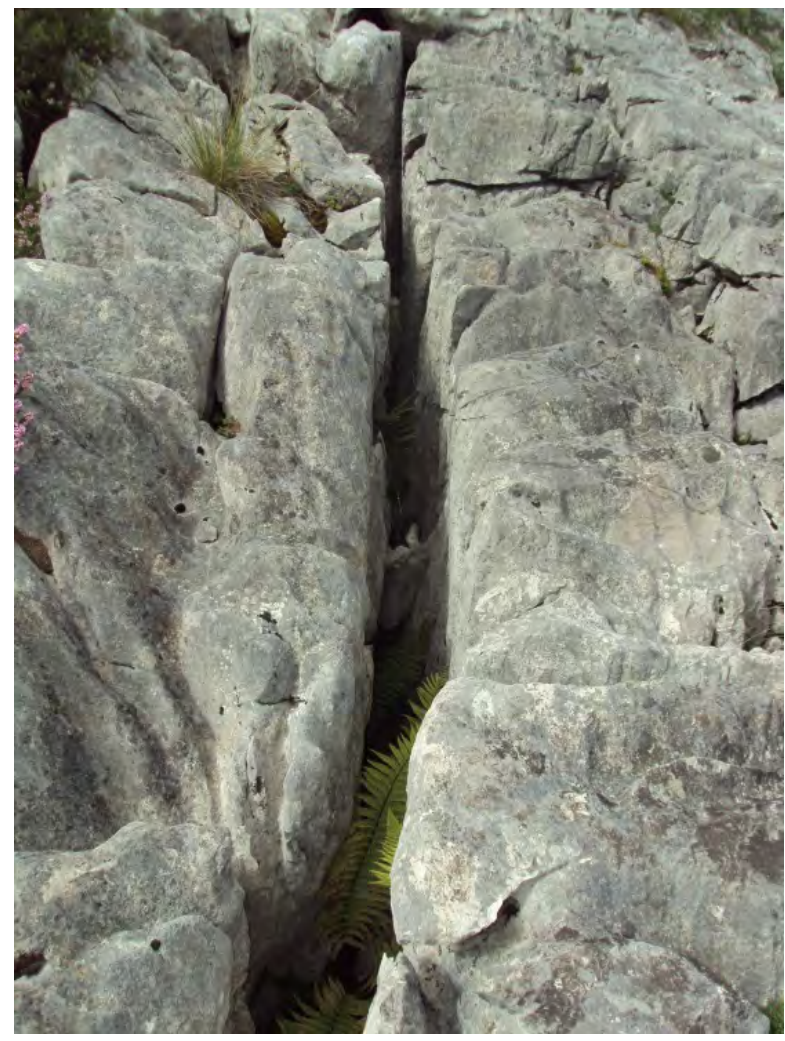

Fig. 12. Kluftkarren labrado sobre "calizas de Picos de Europa" en la Canal de Ternás (Sierra de Cabezu Llerosos).

En cuanto a los lapiaces que progresan al margen de las características estructurales de la roca-lapiaces libres de influencia nival-, estos abundan sobre todo en cotas altas, desarrollándose gracias a los aportes de la fusión de neveros permanentes o que perduran hasta el inicio de la estación cálida, así como de la fusión del manto nival en general. Los diversos tipos de lapiaces libres se forman en función de la inclinación de los afloramientos rocosos (Figuras 13 y 14). Sobre los de mayor pendiente $\left(60-80^{\circ}\right)$ se generan los rillenkarren, integrados por surcos agudos separados entre sí por crestas afiladas. En pendientes más suaves se forman lapiaces en regueros (rinnenkarren), variando su trazado de rectilíneo a meandriforme según se pierde pendiente, formándose los wandkarren y mäanderkarren, respectivamente. Otros tipos de lapiaces libres que aparecen son los nagelbrettkarren -que evolucionan a partir de los rinnenkarren (Figuras 15 y 16)-, así como los trittkarren (Figura 17) y los solution ripples. 


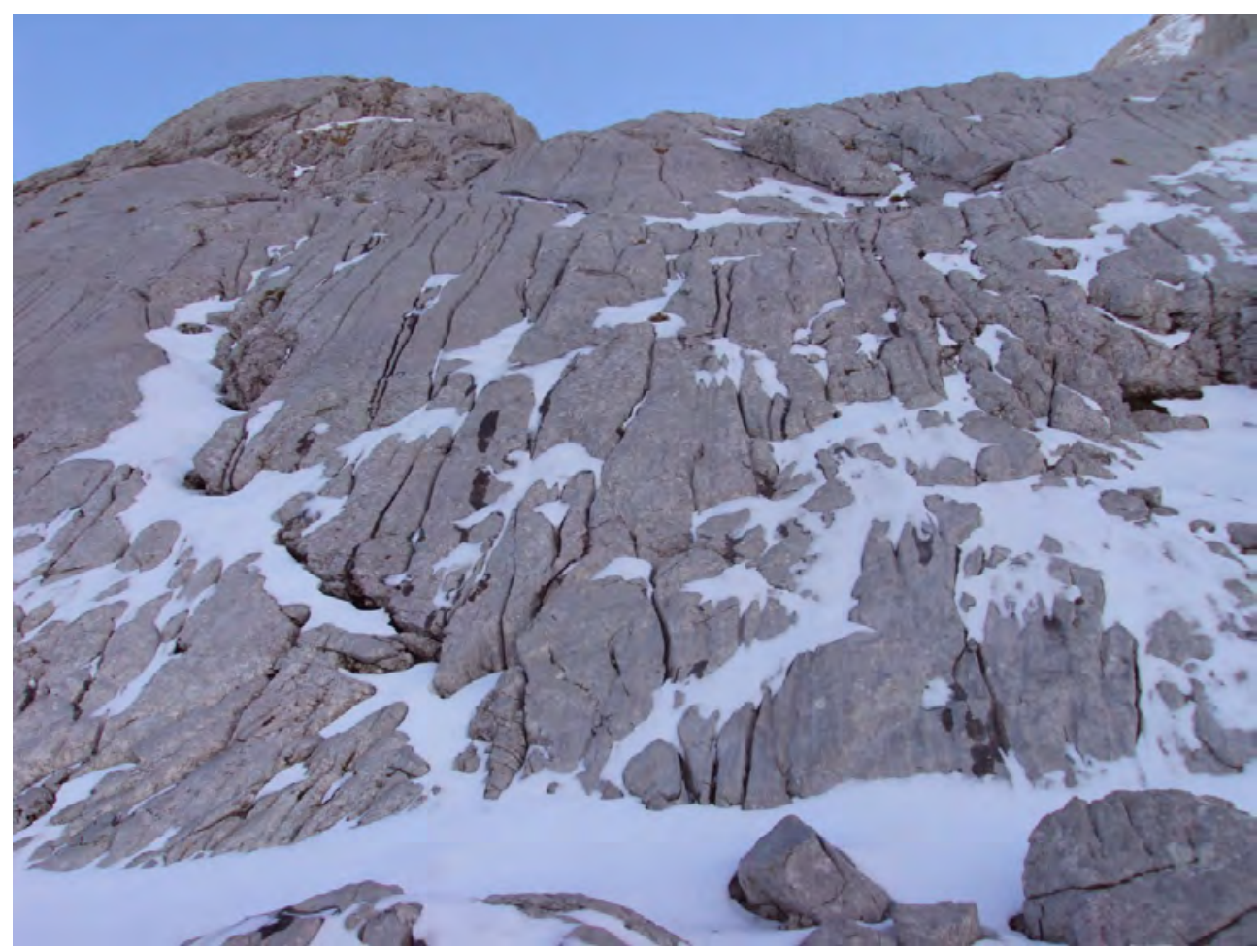

Fig. 13. Lapiaces en regueros y surcos agudos sobre un afloramiento masivo de "caliza de Picos de Europa" en las Barrastrosas. El agua generada por la fusión de la nieve es drenada por la red de pequeños canales, provocando la humectación continua de sus paredes y por consiguiente una efectiva karstificación. 

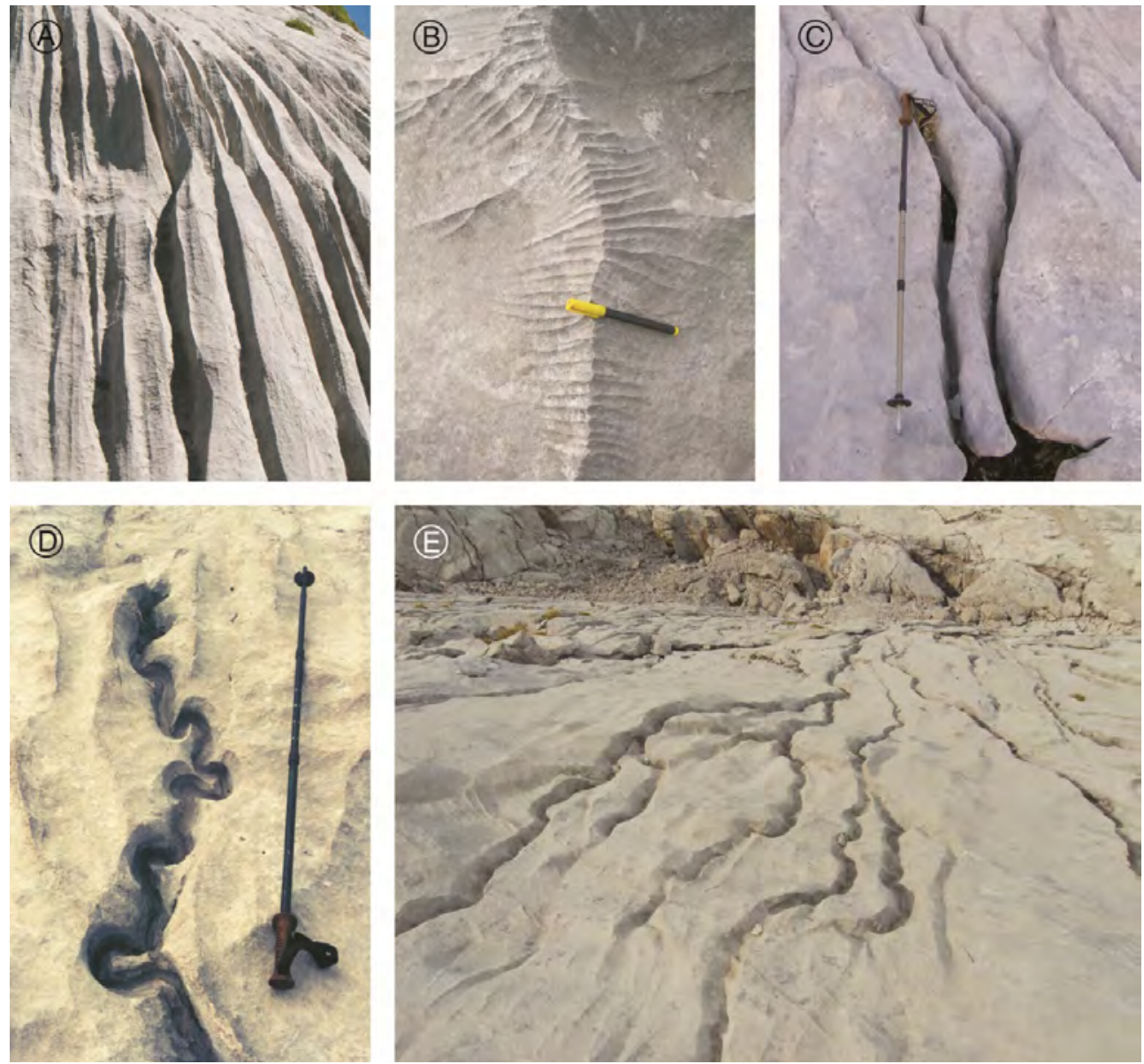

Fig. 14. Diferentes tipos de lapiaces de influencia nival. Lapiaces en surcos agudos (rillenkarren) en las cercanías de la Majada de las Bobias sobre calizas masivas (A); aristas y surcos en rillenkarren en los alrededores de Vegarredonda (B); lapiaces en regueros rectilíneos (wandkarren) en el área las Barrastrosas (C); lapiaz meandriforme (mäanderkarren) en las Cuestas del H.ou Sin Tierri (D); llambrial labrado a favor de un estrato masivo de "calizas de Picos de Europa" en las Barrastrosas (E), sobre el que se han generado lapiaces de tipo rinnenkarren, tanto rectilíneos como meandriformes. 


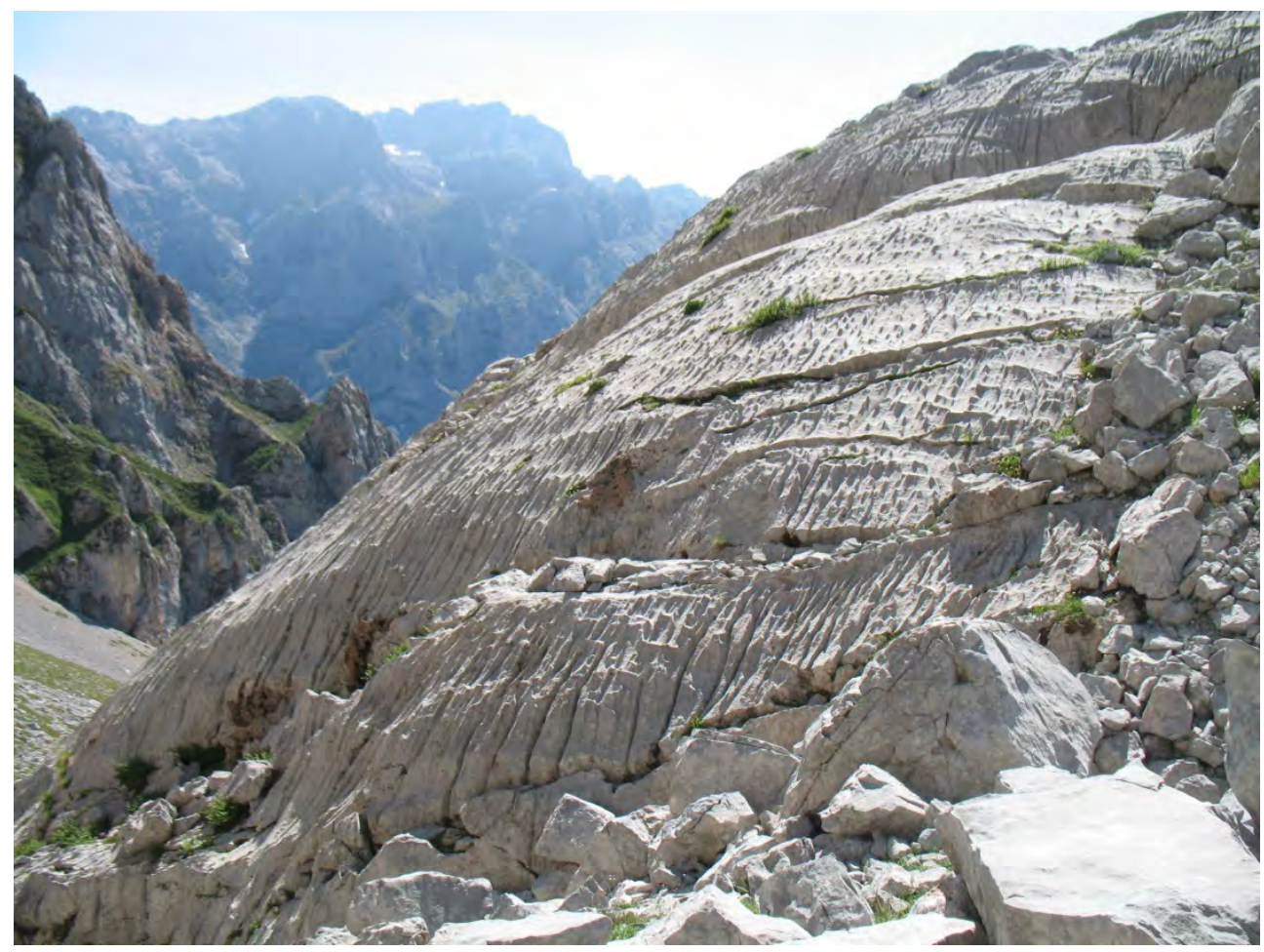

Fig. 15. Transición entre lapiaces de tipo nagelbrettkarren en la parte superior de un afloramiento calizo, y rinnenkarren en la inferior, de mayor pendiente (La Pandona, Pambuches).
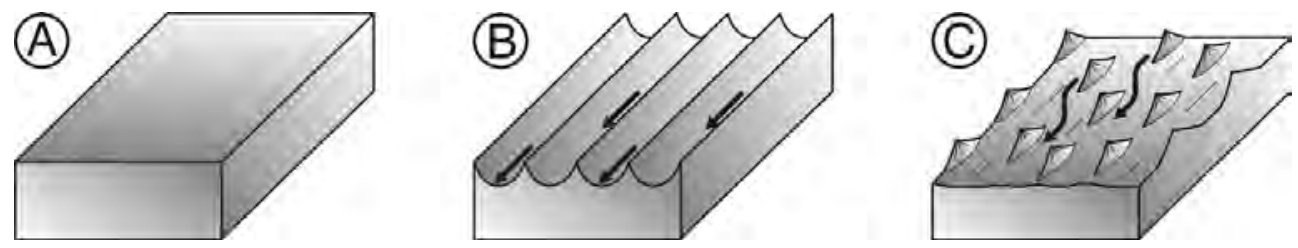

Fig. 16. Evolución de lapiaces de tipo rinnenkarren a nagelbrettkarren según Loiseleur y Salvayre (1978). Sustrato pulido por el hielo glaciar (A); formación de rinnenkarren (B); desarrollo hacia nagelbrettkarren debido a la progresiva coalescencia de los canales, quedando en resalte únicamente algunos sectores de las primitivas aristas intermedias $(\mathrm{C})$. 

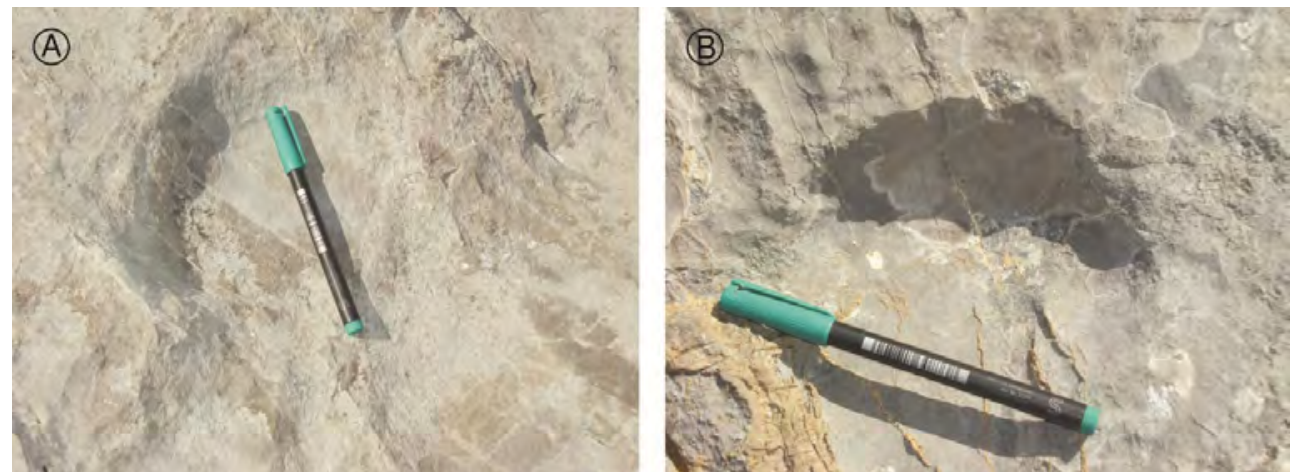

Fig. 17. Ejemplos de trittkarren en las inmediaciones de la Forcadona (A) y en el H.ou Santo (B).

En cuanto a los lapiaces cubiertos destacan las kamenitzas, cuya formación, si bien puede llegar a darse sobre roca al desnudo, es más frecuente bajo la cubierta edáfica. Por esta razón las kamenitzas, que se forman gracias al estancamiento de agua sobre superficies horizontales o subhorizontales (Figura 18), son poco abundantes en las partes altas y medias del Cornión. También se han identificado lapiaces de tipo rundkarren, canales de sección semicircular formados también bajo cubierta edáfica. Tanto estos como los lapiaces en torrecillas son muy frecuentes en los sectores de media y baja altitud, con mayor desarrollo edáfico y de la cubierta vegetal (Figura 19), si bien los últimos no aparecen en los sectores glaciados durante la Última Glaciación, pues han sido decapitadas por el paso de los glaciares. Su génesis sería, por tanto, anterior al Último Ciclo Glaciar del Pleistoceno. Por ejemplo, mientras encontramos numerosos ejemplos de karst en torrecillas entre el valle de Espines, Camplengu y las cercanías de Vega Maor, en este último enclave se ha depositado un complejo morrénico frontal depositado por una lengua del glaciar de Enol a partir del cual los lapiaces en torrecillas desaparecen, dando paso a morfologías características de la abrasión glaciar que aparecen retocadas por otros tipos de lapiaz (rillenkarren, wandkarren, etc.). 

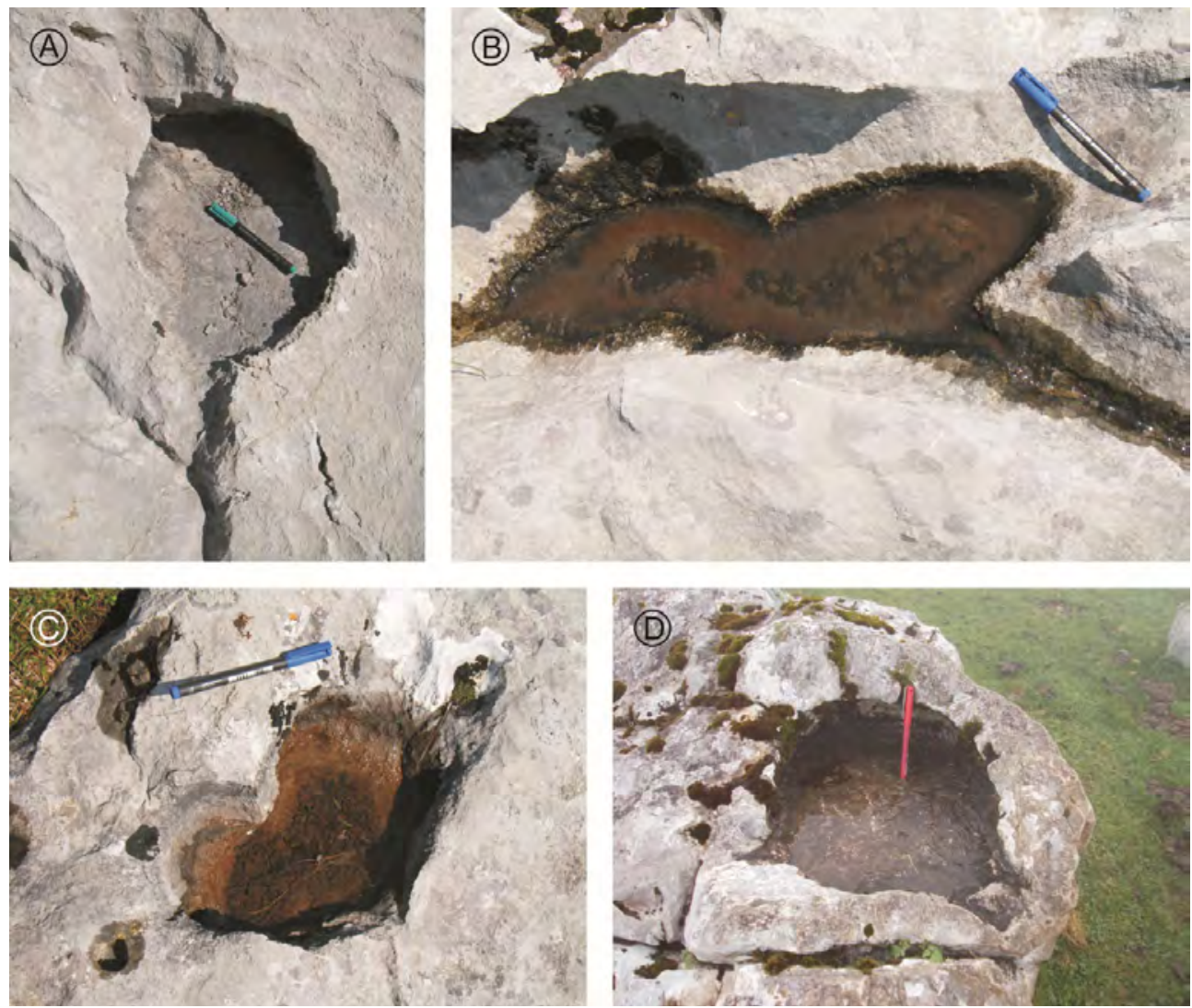

Fig. 18. Ejemplos de kamenitzas en las inmediaciones del H.ou Sin Tierri (A), de la Campera de Chicidi (B y C), y en la Vega de Canraso (D). 


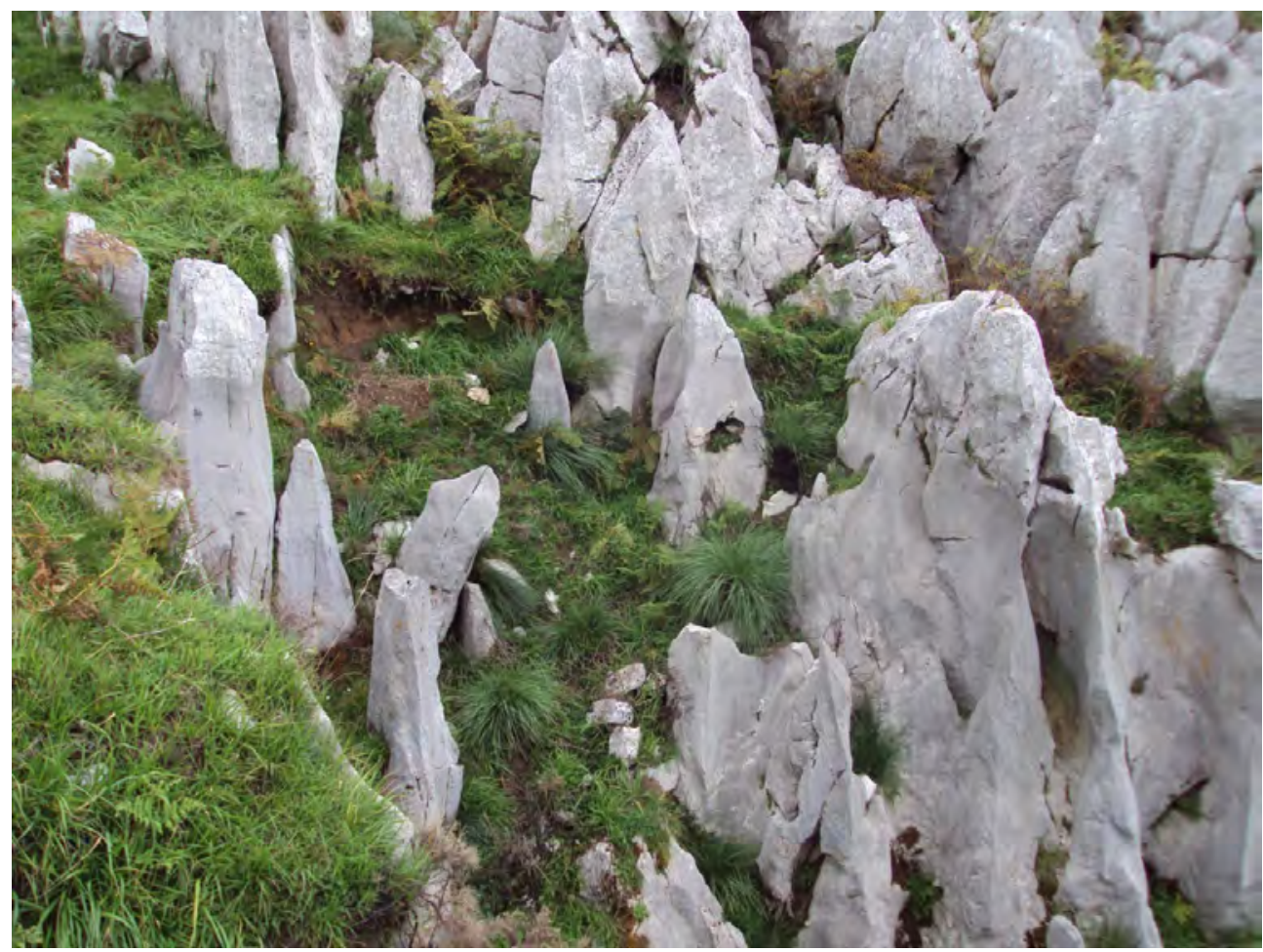

Fig. 19. Karst en torrecillas en la Sierra de Dobros, área que no estuvo ocupada por los hielos durante la Última Glaciación. Salvo en el borde izquierdo de la imagen, la cubierta edáfica ha sido parcialmente desmantelada como consecuencia de la puesta en práctica de actividades mineras, por lo que se puede ver en detalle la morfología característica de las torrecillas. Se diferencia nítidamente la parte cubierta de las mismas, de contornos más suaves y tono gris más oscuro, de la que ha permanecido por encima del suelo, más rugosa y blanquecina.

\subsection{El endokarst}

Al igual que en los otros dos macizos que integran el conjunto de los Picos Europa, en el Macizo del Cornión las cavidades endokársticas adquieren gran desarrollo vertical (por ejemplo los $1232 \mathrm{~m}$ de profundidad en el Sistema del Jitu, $1102 \mathrm{~m}$ en el Sistema Julagua, $986 \mathrm{~m}$ en el Pozo Cuetalbo, $949 \mathrm{~m}$ en el Pozo del Llastral, entre otros (RUIZ-FERNÁNDEZ Y POBLETE, 2012). Esto se debe al notable espesor y disposición tectónica en escamas verticalizadas de las calizas que integran el macizo, junto con el gran desnivel existente entre las áreas más elevadas y el fondo de los desfiladeros. La infiltración de las escorrentías se produce de forma difusa, a través de la profusa red de simas, pozos nivokársticos y depresiones de tamaños diversos existentes en los umbrales, resaltes rocosos y fondo de las depresiones glaciokársticas de los sectores más elevados del Cornión, constituyendo así extensas áreas de captación de las aguas procedentes de la lluvia y la fusión nival. Los conductos endokársticos del macizo tienen una 
organización escalonada, alternando pozos verticales de profundidad variable (métrica a hectométrica), con sistemas de galerías meandriformes situadas a diferentes alturas y tanto inactivas como activas (Ballesteros et al., 2011). Destaca el pozo de los Caínes con $308 \mathrm{~m}$ de desnivel, perteneciente a la Torca de Cabeza Llambrera - Sil de Oliseda (RUIZ-FERNÁNDEZ Y POBLETE, 2012). Aunque los conductos freáticos activos son frecuentes, el interior de las aguas en las cavidades es básicamente vadoso, sobre todo en la base. Estos conductos endokársticos, en general, están inclinados al norte debido a su adaptación a la estructura geológica.

En los sectores de altitud intermedia también encontramos conductos endokársticos de desarrollo principalmente vertical, aunque de menor frofundidad. En las áreas más bajas, sin embargo, la componente horizontal domina sobre la vertical, siendo más frecuente la aparición de galerías que la de simas. Las principales surgencias del macizo son las de Culiembro (1-7 m³ $/ \mathrm{s})$, Reo Molín (1,5 m³/s), Capozo (1 m3/s), Párvora $(1 \mathrm{~m} 3 / \mathrm{s})$, el H.oyo la Madre $(0,5 \mathrm{~m} 3 / \mathrm{s})$, Covadonga $(0,5 \mathrm{~m} 3 / \mathrm{s})$, los Güeyos de la Teya (0,4 m3/s), los Güeyos del Reinazu (0,2 m3/s), Fuente Prieta, los Brazos, la Farfada, los Güeyos del Junjumia y Obar (Ruiz-Fernández y Poblete Piedrabuena, 2012).En el borde meridional del Cornión apenas existen surgencias debido al buzamiento hacia el norte de las sucesivas escamas calcáreas apiladas, y al afloramiento en la vertiente sur del macizo de materiales no karstificables inclinados en la misma dirección (RuizFernández y Poblete Piedrabuena, 2012). En cambio, el agua captada en los sectores de mayor altitud, buscando los niveles de base marcados por la red fluvial, alcanza rápi- damente las surgencias en las áreas bajas y medias de los extremos este, noreste, norte, noroeste y oeste del macizo.

\subsection{La precipitación de los carbonatos: espe- leotemas y depósitos cementados}

Los espeleotemas abundan en el interior de las cavidades endokársticas, donde han sido identificadas, entre otras morfologías de detalle, coladas, cascadas, estalactitas, estalagmitas, columnas, masas estalagmíticas, excéntricas, formas coraloides, y espeleotemas subacuáticos (RUIZ-FERNÁNDEZ Y POBLETE, 2012). Si bien no se han encontrado depósitos tobáceos de entidad dentro del macizo en relación con las surgencias, siendo estos en general muy escasos, la circulación por las laderas de aguas saturadas de carbonatos ha generado otro tipo de depósitos, las gonfolitas. Se trata de brechas calcáreas cementadas características de los Picos de Europa, integradas por derrubios heterométricos sin clasificar (cantos y bloques, a veces de tamaños métricos) de formas angulosas o subangulosas que en el ámbito del Cornión aparecen situadas en la parte inferior de las canales. Es frecuente que alcancen espesores decamétricos y que, fruto de la erosión posterior, tengan un abrupto escarpe en su frente, el cual suele estar karstificado, por lo que en sus paredes abundan las cavidades en cuyo interior aparecen espeleotemas. Estos depósitos suelen adquirir morfologías en cono (bien sea un único abanico o varios coalescentes) o en talud, y es habitual la presencia de bocas de conductos kársticos fósiles sobre ellas. Algunos de estos depósitos cementados, los cuales aparecen a los pies de crestas y paredes rocosas, están integrados en cambio por derrubios homométricos que también han 
sido posteriormente incididos en su frente y bordes laterales por la erosión y que, a menudo, aparecen fosilizados por canchales activos en su parte proximal, lo que evidencia su carácter totalmente heredado, en relación con fases morfogenéticas previas.

\section{DISCUSIÓN}

\section{Interrelación entre el modelado kárstico y otros procesos y formas de modelado}

\subsection{La interrelación entre el karst y el glaciarismo}

El Macizo del Cornión, al igual que el de Ándara y los Urrieles, se ha visto afectado por el glaciarismo cuaternario, formándose en su caso diversos aparatos glaciares cuyos frentes alcanzaron altitudes de entre 550 y 1480 m durante la fase de máxima extensión del hielo dentro de la Última Glaciación (RUIZ-FERNÁNDEZ, 2015; RUIZ-FERNÁNDEZ y GARCÍA-HERNÁNDEZ, 2018). La omnipresente morfología kárstica y las huellas glaciares heredadas, tanto erosivas como sedimentarias, son las formas de relieve de mayor entidad y repercusión paisajística de los Picos de Europa. Entre ambos tipos de modelado se han producido interferencias y, sobre todo, persistentes y estrechas relaciones de interdependencia que van a ser estudiadas a continuación.

La existencia de un relieve previo a la ocupación de este espacio por las masas de hielo, ha condicionado la dinámica de los propios aparatos glaciares. En este aspecto, las formas kársticas han jugado un importante papel, pues el retroceso glaciar fue entrecortado por la topografía extremadamente rugosa e intrincada característica del karst, en la que grandes cubetas glacio- kársticas se alternan con umbrales conformados a partir de promontorios calcáreos en resalte. Por ello, adosado a los umbrales o bien cubriendo el fondo de las depresiones glaciokársticas, frecuentemente aparece material morrénico que, en ocasiones, responde al retroceso de las masas de hielo por cuestiones dinámicas, no teniendo por qué corresponderse, por tanto, con una respuesta climática. La formación de neveros y la pervivencia de lentejones de hielo glaciar durante un tiempo favoreció asimismo la acumulación de derrubios en los h.ous (MIOTKE, 1968; CASTAÑÓN Y FROCHOSO, 1994).

Por otro lado, la expansión de los glaciares durante la Última Glaciación borró la morfología kárstica anterior, que solamente se conservó en los ámbitos del Cornión que no estuvieron ocupados por los hielos. Las depresiones kársticas generadas previamente en los sectores de alta y media montaña fueron ocupadas por potentes masas de hielo de flujo centrífugo con respecto al macizo, que ejercieron una importante acción de abrasión y sobreexcavación sobre ellas. Esto contribuyó a ampliar su perímetro y su profundidad todavía más, hasta dar lugar finalmente a las grandes hoyas de génesis mixta, kárstica y glaciar, tan características de estas montañas. El origen mixto glaciokárstico de estas grandes depresiones fue puesto de manifiesto precisamente en los $\mathrm{Pi}$ cos de Europa por autores como MIOTKE (1968) y SMART (1986). Sin embargo, la gran entidad paisajística de las depresiones glaciokársticas, su morfología, su singular morfogénesis mixta (karstificación, excavación glaciar, erosión de las aguas de fusión provenientes de glaciares en retroceso), y su evolución reciente postglaciar (retoque posterior por las aguas de fusión nival, in- 
tervención de la crioclastia, etc.), ha suscitado también el interés de otros investigadores como NICOD (1975, 1976), NICOD et al. (1978) y MAIRE (1990), que estudiaron tales formas en diversos macizos calcáreos de los Alpes como los de Marguareis, Oserot, Dévoluy o los Dolomitas. En las partes más altas del Macizo del Cornión las citadas cubetas constituyeron enclaves muy favorables para la acumulación de nieve y su posterior transformación en hielo glaciar, funcionando como verdaderos circos, tal y como han señalado MIOTKE (1968), SMART (1986), GALE Y HOARE (1997) y FROCHOSO Y CASTAÑÓN (1998).

El avance glaciar modificó también las condiciones de infiltración del agua dentro del endokarst. En las áreas que fueron ocupadas por el hielo el drenaje pasó a concentrarse en unas pocas cavidades, mientras que en los sectores bajos del macizo continuó siendo difuso. En el ámbito glaciado, los voluminosos aportes hídricos dirigidos hacia el interior del macizo por molinos de fusión y cauces subglaciares, retrabajaron parte de los conductos preexistentes, ensanchándolos y profundizándolos, e incluso fueron capaces de crear nuevas cavidades a favor del entramado estructural (MIOTKE, 1968; SMART, 1984 y 1986; SENIOR,
1987; ALONSO, 1991; ROSSI, 2004; VERHEYDEN et al., 2007).

La sucesiva retirada de los hielos formados durante la Última Glaciación hacia ámbitos de mayor altitud fue acompañada por un avance de la karstificación (y la morfodinámica periglaciar) desde las áreas deglaciadas más bajas a las partes altas, así como por un nuevo cambio en las condiciones de drenaje. En las zonas que paulatinamente fueron quedando libres de hielo, el agua ya no se sumirá al interior del macizo por unas pocas cavidades, sino que percolará nuevamente por multitud de oquedades de diversa escala y morfología. Es interesante destacar que las abundantes escorrentías provenientes de la ablación de los frentes glaciares en retroceso, contribuyeron notablemente al progreso de la karstificación, especialmente en el caso de las depresiones glaciokársticas y los conductos que se abren en el fondo de las mismas (MIOTKE, 1968; SMART, 1984 y 1986; ALONSO, 1991). Pero en general, prácticamente todas superficies rocosas trabajadas previamente por la abrasión glaciar (las paredes y el fondo de las cubetas y las artesas, los umbrales, las rocas aborregadas, etc.) serán retocadas progresivamente por la disolución kárstica (Figura 20), generándose extensos campos de lapiaces e incontables dolinas. 


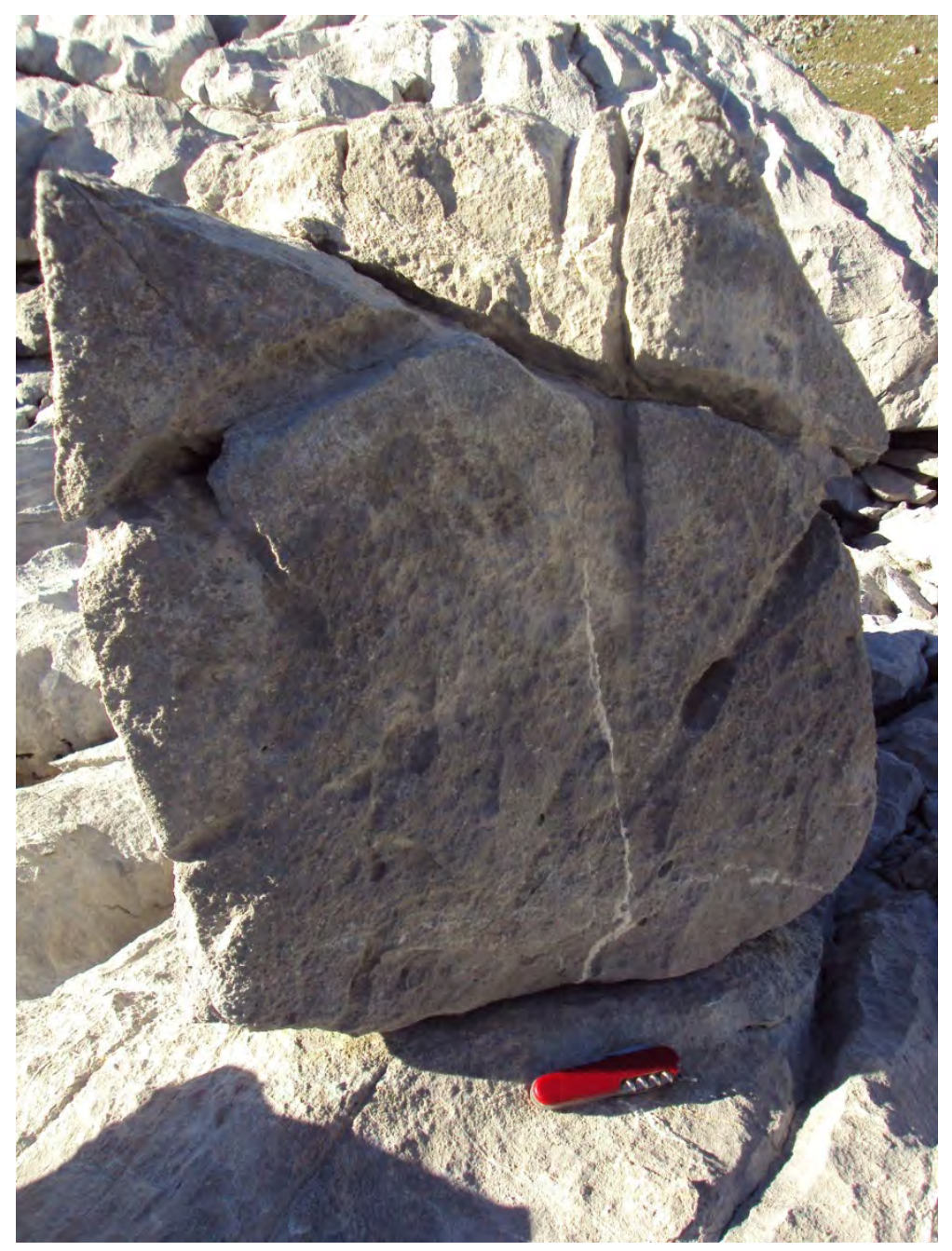

Fig. 20. Bloque errático sobre pedestal en las inmediaciones de Vega Huerta. Tras la retirada del hielo glaciar la superficie calcárea adyacente al bloque ha sido rebajada por la karstificación, mientras que debajo de éste, debido a su acción protectora, el impacto de la disolución ha sido mínimo.

Por tanto, la ablación kárstica postglaciar ha borrado casi por completo las huellas glaciares erosivas de detalle (estrías y acanaladuras), salvo en los sectores del macizo ocupados por glaciares durante la Pequeña Edad del Hielo (PEH) (cara Norte de Peña
Santa de Castilla, La Forcadona y Cemba Vieya; González-Trueba, 2007b). En ellos la karstificación prácticamente no ha tenido tiempo de progresar, por lo que la morfología glaciar erosiva es muy fresca y nítida (Figura 21). En el resto de la superficie gla- 
ciada, incluida la atribuida al Tardiglaciar (SERRANO et al., 2013; RUIZ-FERNÁNDEZ et al., 2016; RUIZ-FERNÁNDEZ Y GARCÍA-HERNÁNDEZ，2018), únicamente se conservan estrías y acanaladuras sobre algunos afloramientos rocosos protegidos por material morrénico $\mathrm{u}$ otro tipo de derrubios, que posteriormente han sido puestos al descubierto debido a la apertura de sendas (Las Barrastrosas, Arnaedo, etc.), así como en las paredes de unas pocas artesas y canales; especialmente cuando en ellas existen extraplomos que han permitido que las citadas formas erosivas quedasen a resguardo de la acción del agua, y por tanto de la corrosión kársticas (Canal de Ozania) (RUIZ-FERNÁNDEZ et al., 2016; RUIZFERNÁNDEZ Y GARCÍA-HERNÁNDEZ, 2018).

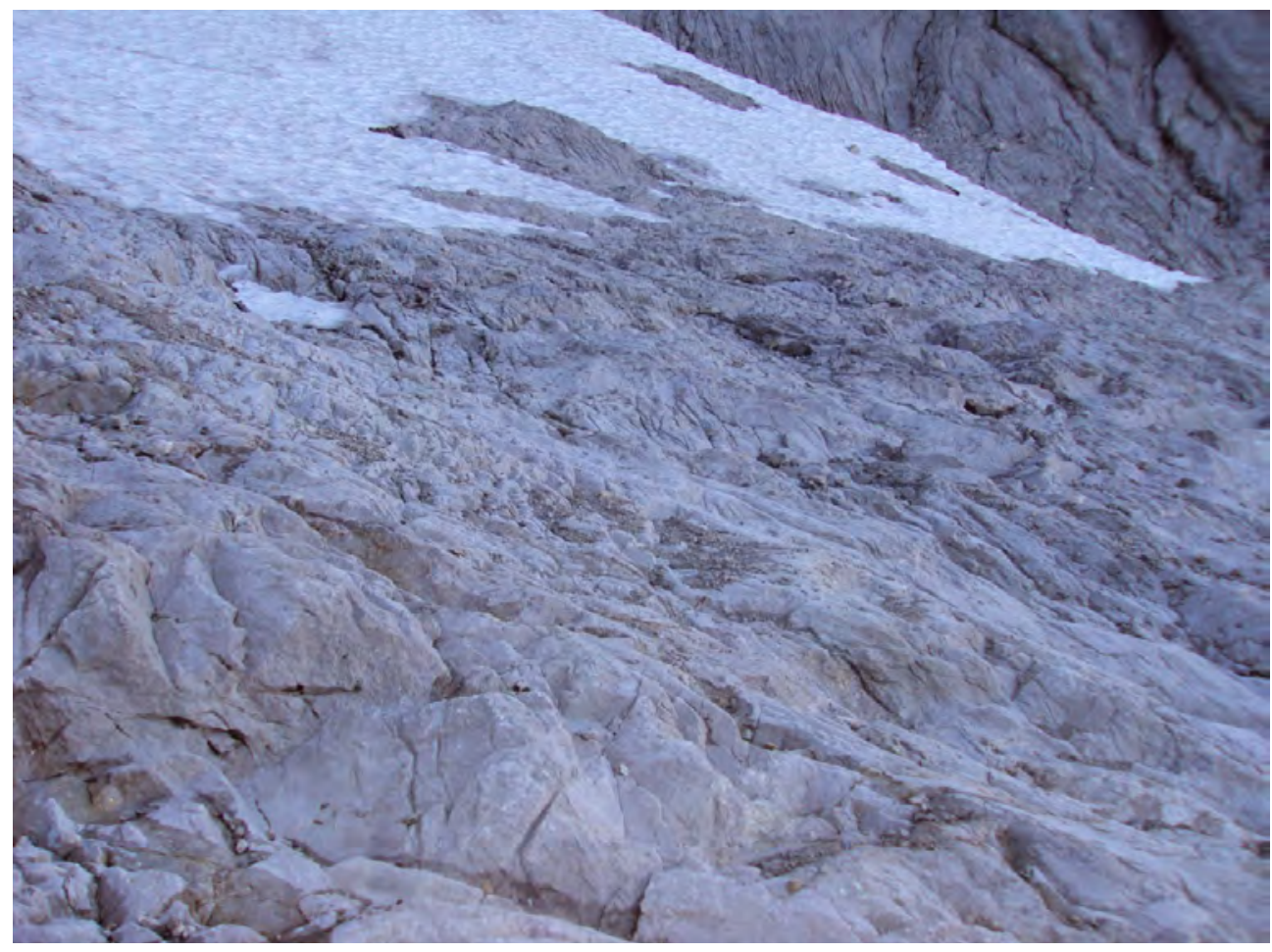

Fig. 21. Imagen parcial del lecho ocupado durante la PEH por el glaciar de la Cemba Vieya. En detalle, la superficie rocosa muestra huellas muy claras de la abrasión ejercida por la antigua masa de hielo, con numerosos sectores pulidos y estriados. En cambio, las formas derivadas de la disolución de la caliza aún son poco visibles. Los escasos lapiaces que se han generado, de carácter incipiente y vinculados a la fusión estacional del nevero emplazado actualmente en el fondo del circo, son principalmente de tipo rinnenkarren. Por contraposición, el espacio situado inmediatamente a los pies del glaciar de la $\mathrm{PEH}$, que permaneció libre de hielo desde el Tardiglaciar (RUIZ-FERNÁNDEZ et al., 2016), está intensamente retocado por lapiaces y pozos nivales. Véase, al respecto, las figuras $13,14 \mathrm{C}$ y $14 \mathrm{E}$. 
1.1. Influencia de las condiciones morfoclimáticas actuales de la alta montaña en la evolución del modelado kárstico: interrelación entre el karst y la morfodinámica periglaciar

Como se ha citado con anterioridad, el karst que se desarrolla actualmente en los sectores elevados de los Picos de Europa es el nival o de montaña, que en nuestro país está presente también en otros macizos y sierras calizas de las Montañas Cantábricas y los Pirineos. Este tipo de karst se caracteriza por precipitaciones abundantes (iguales $\mathrm{o}$ superiores a $2000 \mathrm{~mm}$ anuales) y en gran medida en forma de nieve, y temperaturas bajas, lo que favorece la disolución y limita la evapotranspiración (GARCÍA-CODRÓN, 1989; JULIÁN, 1994). En estos ambientes la karstificación es un proceso muy eficaz que da lugar a formas muy desarrolladas y de rápida evolución, que coexisten e interactúan con otros procesos y formas de modelado como los periglaciares y los glaciares. Como muestra de esa interacción y de la intensidad y eficacia de la karstificación nival, cabe citar el estudio realizado por CHUECA Y JULIÁN (1999) en los glaciares occidental y oriental de Infiernos (Pirineo Central), en el que señalan la formación de un campo de dolinas muy desarrollado sobre depósitos morrénicos de la $\mathrm{PEH}$, habiendo transcurrido solamente entre 170 y 180 años entre el último máximo de la PEH y la actualidad.

Actualmente en las áreas más elevadas del Cornión se registran precipitaciones medias anuales superiores a los $2000 \mathrm{~mm}$ y probablemente incluso a los $3000 \mathrm{~mm}$ como apunta LAUTENSACH (1964), siendo en gran medida en forma de nieve. La precipitación nival directa y la acción de redistribución por el viento y por el desencadenamiento de avalanchas hace que en los grandes h.ous se alcancen espesores medios de nieve de entre 3 y $5 \mathrm{~m}$; aunque en enclaves favorables y años de abundantes precipitaciones nivales se pueden acumular volúmenes muy superiores. Los datos obtenidos mediante el uso de termorregistradores muestran que en la alta montaña el manto nival perdura aproximadamente unos 8 meses (GONZÁLEZ-TRUEBA Y SERRANO, 2010; RUIZ-FERNÁNDEZ et al., 2017). Todo ello asegura una gran disponibilidad de aguas de fusión y por tanto una eficaz karstificación.

Por otro lado, las temperaturas medias anuales son bajas. MUÑOZ (1982) sitúa la isoterma anual de $0^{\circ} \mathrm{C}$ para el conjunto de Asturias entre 2400 y $2500 \mathrm{~m}$, y la de $2,7^{\circ} \mathrm{C}$ a $2000 \mathrm{~m}$ de altitud. Según nuestros datos (RUIZ-FERNÁNDEZ et al., 2014 y 2017), en el periodo comprendido entre noviembre de 2007 y octubre de 2011 la temperatura media registrada en las inmediaciones de una pared rocosa (interfaz aire-roca) a $2200 \mathrm{~m}$ de altitud fue ligeramente superior a $3^{\circ} \mathrm{C}$; mientras que sobre los derrubios que recubren el helero de la Forcadona hemos obtenido temperaturas medias anuales incluso ligeramente inferiores a $0^{\circ} \mathrm{C}$ (RUIZFERNÁNDEZ et al., 2017). En cambio, las temperaturas mínimas no son extremadamente bajas y raramente descienden de $-10^{\circ} \mathrm{C}$ (mínima absoluta de $-14,3^{\circ} \mathrm{C}$ para el periodo 2006-2011). Por su parte los ciclos de hielo-deshielo son escasos a nivel de las formaciones superficiales (entre 0 y 36 en función de altitudes, orientaciones y posiciones topográficas), pues la nieve ejerce un papel protector, aislando al suelo de la temperatura del aire; mientras que su impacto sobre las cretas y paredes rocosas es mucho más significativo, habiéndose registrado hasta 130 ciclos en 2007/2008 en una pared 
rocosa situada en las cercanías de la Forcadona (RUIZ-FERNÁNDEZ et al., 2014).

Las cuantiosas precipitaciones y las temperaturas frías propias de la alta montaña del macizo, así como la gran abundancia de aguas de fusión nival, favorecen la existencia de tasas de karstificación verdaderamente altas. En los Picos de Europa cabe citar las aportaciones al respecto de COLLIGNON (1985) y de GARAY Y MORRELL (1989). Estos últimos autores calcularon las tasas de disolución de diversas regiones kársticas españolas tanto atlánticas como mediterráneas, utilizando el método hidroquímico (CORBEL, 1959), y han obtenido la tasa más alta precisamente en los Picos de Europa, con 148 mm/milenio o m3/Km2/ año (ambas expresiones son equivalentes, aunque diversos autores sugieren que es más apropiado utilizar la segunda) (Tabla 2). Por su parte COLLIGNON (1985) cita una tasa de ablación kárstica para el conjunto de los Picos de Europa de $100 \mathrm{~m}^{3} / \mathrm{año} / \mathrm{Km}^{2}$. Como se puede observar en Tabla 2, existe una clara dependencia entre la tasa de disolución y las precipitaciones medias anuales (LÓPEZ-MARTÍNEZ, 1984; GARAY Y MORRELL, 1989), si bien hay otros facto- res intervinientes que es necesario tener en cuenta como el tipo de litología, la estructura, la existencia o inexistencia de cubierta edáfica y vegetal, la temperatura, la distribución temporal de las precipitaciones o la abundancia de nieve.

Es necesario mencionar finalmente que con frecuencia la disolución se combina con la crioclastia, interactuando y beneficiándose ambos procesos de forma recíproca, pues, tal y como argumenta NICOD (1972), la disolución genera numerosas grietas y rugosidades propicias a la acción de la gelifracción, y a su vez las fisuras y oquedades agrandadas por el hielo son enclaves muy favorables para la concentración de la corrosión kárstica. Esta interacción es lo que MAIRE (1990) definió como gelidisyunción. En este sentido, CASTAÑÓN Y FROCHOSO (1998) citan la existencia de procesos de gelidisyunción y gelidescamación en las áreas elevadas del Macizo de los Urrieles, responsables de la formación de finas lascas ante la saturación por el agua de fusión nival de los innumerables huecos, tabiques y aristas cortantes y escabrosas que integran el roquedo calcáreo corroído por la disolución, y la posterior actuación de ciclos de hielo-deshielo de duración diaria. 


\begin{tabular}{|l|l|c|c|l|}
\hline Localización & Litología y edad & $\begin{array}{l}\text { Precipitación } \\
\text { Media anual } \\
(\mathbf{m m})\end{array}$ & $\begin{array}{l}\text { Tasa de } \\
\text { disolución } \\
\left(\mathbf{m}^{3} / \mathbf{K m}^{2} / \mathbf{a n ̃ o}\right)\end{array}$ & Referencia \\
\hline $\begin{array}{l}\text { Picos de Europa } \\
\text { (Asturias) }\end{array}$ & Calizas carboníferas & $>2000$ & $148 / 100$ & $\begin{array}{l}\text { Garay y Morrell (1989)/ } \\
\text { Collignon (1985) }\end{array}$ \\
\hline $\begin{array}{l}\text { Llantones } \\
\text { (Gijón, Asturias) }\end{array}$ & Calizas jurásicas & 1000 & 31 & Garay y Morrell (1989) \\
\hline $\begin{array}{l}\text { Ribadesella } \\
\text { (Asturias) }\end{array}$ & Calizas carboníferas & 1400 & 61 & Garay y Morrell (1989) \\
\hline $\begin{array}{l}\text { Cabuérniga } \\
\text { (Cantabria) }\end{array}$ & Calizas jurásicas & 1500 & 52 & Garay y Morrell (1989) \\
\hline $\begin{array}{l}\text { Aralar-Mendi } \\
\text { (Guipúzcoa) }\end{array}$ & Calizas cretácicas & 2000 & 69 & Ugarte y Ugalde (1985) \\
\hline $\begin{array}{l}\text { Piedra de San Martín } \\
\text { (Navarra, Huesca y } \\
\text { Francia) }\end{array}$ & Calizas cretácicas & 2500 & 125 & López-Martínez (1984) \\
\hline
\end{tabular}

Tabla 2. Tasas de karstificación de diversos sectores del Norte de España obtenidas mediante el método hidroquímico.

\section{ETAPAS EN LA EVOLUCIÓN DEL RELIEVE KÁRSTICO DEL MACIZO DEL CORNIÓN}

La morfología kárstica actual del Cornión es el fruto de una dilatada evolución temporal en la que se sucedieron distintas condiciones morfoclimáticas $\mathrm{y}$, en consecuencia, actuaron diversos agentes morfogenéticos. Los testimonios morfológicos y sedimentarios descritos en las páginas precedentes permiten diferenciar tres grandes fases en la evolución del relieve kárstico de este macizo: una preglaciar, una segunda etapa de karstificación coincidente con la expansión glaciar y, por último, otra de karstificación postglaciar (MIOTKE, 1968; RUIZ-FERNÁNDEZ Y SERRANO, 2011). A continuación, se sintetizarán las características principales de cada una de ellas, así como las morfologías y los depósitos asociados.

\subsection{Karst preglaciar}

Durante esta fase los testimonios morfológicos exokársticos más antiguos son el karst en pináculos existente en el entorno de las minas de Buferrera, desarrollado bajo depósitos arcillosos con abundantes nódulos de hierro (Figura 22). Este tipo de karst, generado presumiblemente bajo unas condiciones paleoclimáticas cálidas y húmedas, ha sido atribuido por diversos autores al Terciario (HOYOS, 1979; CASTAÑÓN, 1989; HOYOS Y HERRERO, 1989). En dicha etapa se gestarían también las formas exokársticas mayores. Algunas de ellas fueron retrabajadas posteriormente por los glaciares cuaternarios. Por su parte, las morfologías endokársticas más antiguas que se conservan son algunos niveles de galerías freáticas fósiles colgadas cientos de metros sobre el nivel freático actual de sus respectivas simas, y en algunos casos incluso más de mil metros, como sucede en el Sistema de 
Jitu (LAVERTY Y SENIOR, 1981). Como ya se ha citado, estos conductos podrían estar relacionados con las primeras fases de la karstificación del macizo, así como con el inicio de la incisión de las principales gargantas (LABERTY Y SENIOR, 1981; SMART, 1984; SENIOR, 1987). La conservación de sedimentos integrados por materiales del Pérmico en el interior de algunas cavidades, que prácticamente han desaparecido en superficie, evidencia que se formó una cobertera sedimentaria posthercínica que fue desmantelada posteriormente, y pone de manifiesto asimismo el desarrollo de una fase de karstificación antigua cuando aún se conservaban en superficie los materiales pérmicos (SMART, 1984; SENIOR, 1987; VERHEYDEN et al., 2007).

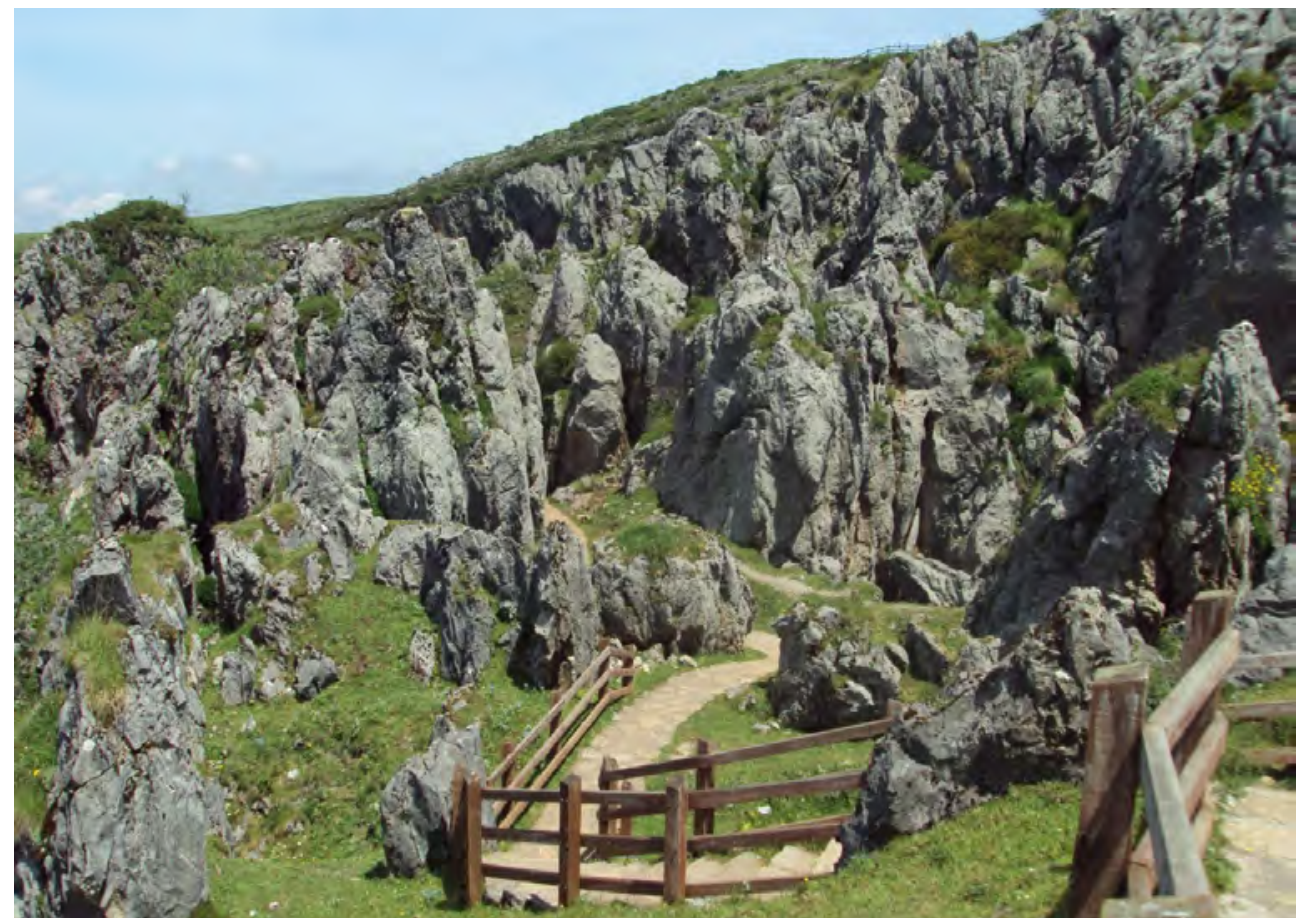

Fig. 22. Detalle de los lapiaces en pináculos de las minas de Buferrera.

\subsection{Karst glaciar}

Esta etapa se desarrolló aproximadamente entre hace 50000 y 11000 años (Pleistoceno tardío; RUIZ-FERNÁNDEZ Y SERRANO, 2011). Los glaciares se adaptaron al relieve previo, aprovechando todos aquellos sectores y morfologías favorables a la acumulación de la nieve y su transformación posterior en hielo. Así, numerosos recuencos existentes en altitud fueron convertidos en circos glaciares, las depresiones kársticas preexistentes fueron ensanchadas y profundizadas, y los antiguos valles secos 
de origen kárstico fueron remodelados en artesas glaciares. En esta fase el drenaje hacia el interior de la masa calcárea se concentró en unas pocas cavidades situadas en el fondo de las depresiones glaciokársticas y en los umbrales, por las que se sumían los ríos subglaciares y las aguas procedentes de los molinos de fusión. Esta circulación hídrica concentrada y de tipo esencialmente vadoso remodeló las cavidades endokársticas preexistentes, y posiblemente generó otras nuevas a favor de la estructura (MIOTKE, 1968; SMART, 1984 y 1986; SENIOR, 1987; ROSSI, 2004; VERHEYDEN et al. 2007). Los cauces proglaciares procedentes de los frentes glaciares también fueron a parar a los conductos abiertos en el fondo de las cubetas glaciokársticas, ejerciendo una labor de ablación kárstica muy eficaz. Muchas cavidades quedaron sin drenaje, taponadas por till y/o hielo glaciar (MIOTKE, 1968). En cambio, en las áreas no glaciadas el drenaje siguió siendo difuso.

\subsection{Karst postglaciar}

Esta fase se desarrolla esencialmente en el Holoceno, y se caracteriza por el desarrollo de un karst nival en las partes elevadas del macizo. Tras la retirada de los hielos el drenaje de las escorrentías hacia el interior de la masa calcárea pasa a ser nuevamente difuso, con numerosos conductos de diverso tamaño y morfología que drenan rápidamente el flujo hídrico hacia las principales surgencias, ubicadas en la periferia del macizo. En la alta montaña las tasas de disolución son altas, incentivadas por unas precipitaciones muy elevadas. La ablación kárstica interacciona con la crioclastia, con incidencia fundamentalmente a escala de detalle (lapiaces). Como consecuencia se forman pozos nivokársticos, así como lapiaces de influencia nival que evolucionan rápidamente al margen de las características estructurales de la roca caliza (rillenkarren, wandkarren y mäanderkarren), junto con otros fisurales (splitkarren y kluftkarren). En cambio, en la media y la baja montaña se desarrolla un karst cubierto de tipo templado oceánico. Gran parte de este ámbito no ha estado afectado por los glaciares cuaternarios, por lo que la morfología kárstica es rica, conservándose formas heredadas de periodos previos. Las dolinas, que adquieren aquí diversas morfologías (platillo, artesa, cubeta, etc.) y las uvalas, tienen su fondo tapizado de abundantes arcillas de descalcificación. Predominan los lapiaces de tipo rundkarren y en torrecillas, y también los de tipo estructural (splitkarren y kluftkarren), estando presentes a su vez las kamenitzas.

\section{LAS FRANJAS KÁRSTICAS DEL MACIZO OCCIDENTAL DE LOS PICOS DE EUROPA}

Como ha quedado patente, el relieve kárstico del Cornión está integrado por una amplia variedad de morfologías y procesos que, como sucede en el caso de otros tipos de geoformas y procesos, presentan variaciones con el aumento o el descenso de la altitud. Así, hemos diferenciado en el macizo cuatro franjas kársticas organizadas en función de dicho factor:

\section{1. Área de karst cubierto oceánico de media montaña}

Se trata de un ámbito que no ha estado ocupado por el hielo durante la Última Glaciación. Por tanto, la morfología kárstica previa no ha sido borrada o remodela- 
da, como aconteció en los sectores situados a mayor altitud, y ha ido evolucionando a lo largo del Cuaternario. Los lapiaces son fundamentalmente estructurales y cubiertos. Predominan especialmente los de tipo rundkarren, splitkarren y kluftkarren, así como los lapiaces en torrecillas y los oquerosos (hohlkarren). Las dolinas, tapizadas generalmente por arcillas de descalcificación, presentan diversas morfologías (Figura 23). Abundan las uvalas, que están recubiertas igualmente por espesos mantos arcillosos. Las cavidades son de dimensiones mucho más modestas que en las áreas elevadas del macizo y, en ellas, los conduc- tos de componente horizontal dominan sobre los verticales. El ritmo de la karstificación guarda una estrecha relación con la abundancia de suelos y vegetación, y es más reducido que en los sectores de alta montaña. Esta franja kárstica está bien representada en los bordes del macizo, siempre por debajo del ámbito alcanzado por los glaciares cuaternarios, así como en las sierras de Cabezu Llerosos y Beza (fuera también del área que estuvo glaciada en estos dos conjuntos), y en las alineaciones de Dobros, Covadonga y Amieva, que en este caso no estuvieron ocupadas por el hielo durante la última Glaciación. 


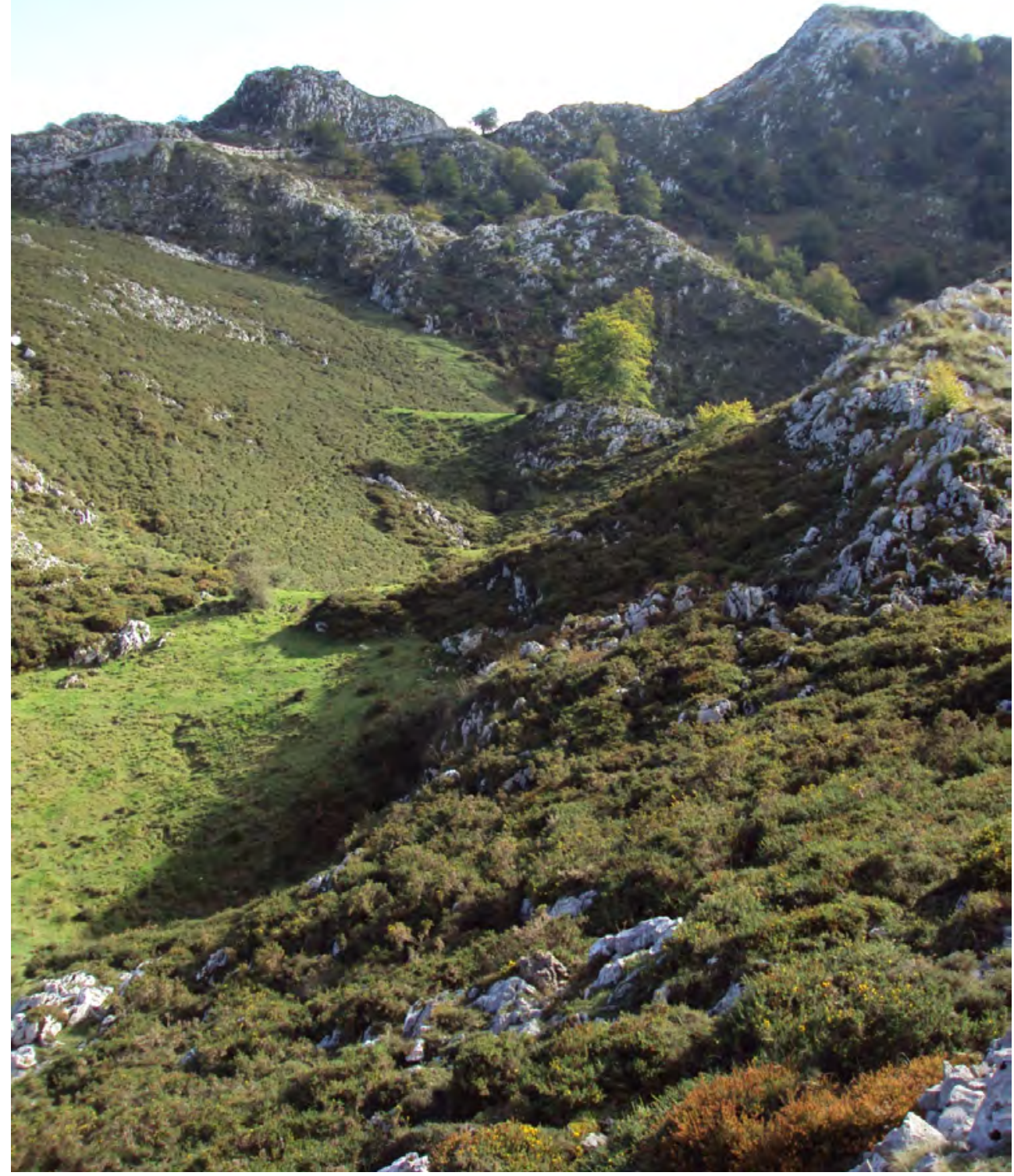

Fig. 23. Paisaje kárstico de media montaña en las inmediaciones del Mirador de la Reina. 


\subsection{Sector de los frentes glaciares y las cube- tas glaciokársticas bajas}

El segundo ámbito diferenciado se circunscribe al área de la máxima expansión de los glaciares durante la Última Glaciación y a los sectores localizados inmediatamente hielos arriba. El límite altitudinal entre las dos primeras franjas kársticas citadas varía, debido a la diferencia de altitud de unos frentes glaciares con respecto a otros, así como por la existencia de áreas no glaciadas entre medias, por lo que lo situamos entre 800 y 1200 m, con la excepción de varias lenguas glaciares encauzadas por canales que alcanzaron cotas extraordinariamente bajas en el borde Este del macizo (600 a $550 \mathrm{~m}$ ), y de otra que descendió solamente hasta $\sim 1400 \mathrm{~m}$ (RUIZ-FERNÁNDEZ Y GARCÍA-HERNÁNDEZ, 2018). En esta segunda área los suelos y la cubierta vegetal ocupan aún notable superficie, estando desarrollados generalmente sobre till. Son frecuentes las depresiones glaciokársticas de grandes dimensiones y fondo relleno de sedimentos, que cuentan con turberas y cortos cursos de agua alimentados por surgencias que se vuelven a sumir rápidamente (Vega el
Bricial, Vega el Paré, etc.). En relación con los frentes y ámbitos distales de los aparatos glaciares, cabe destacar la existencia de importantes surgencias (Güeyos del Junjumia, Güeyos de la Teya, la Farfada, etc.).

\subsection{Desierto kárstico}

Se trata de una franja definida por el predominio absoluto de la morfología y los procesos kársticos, así como por la práctica inexistencia de suelos, vegetación y otros procesos o formas de relieve. En efecto, apenas hay depósitos morrénicos ni pedreras de entidad. Es un paisaje áspero en extremo en el que la roca caliza in situ está horadada por multitud de pequeñas depresiones kársticas dirigidas por el entramado estructural, así como por campos de lapiaz. En este sector, que se desarrolla en altitudes comprendidas entre 1400 y $1700 \mathrm{~m}$, comienza a ser patente la influencia nival, especialmente en el caso de los lapiaces. Se trata de un área caracterizada por la captación difusa de las precipitaciones y el agua de fusión nival pero, a diferencia de la anterior, no hay surgencias, dominando casi en exclusiva la infiltración hídrica. 


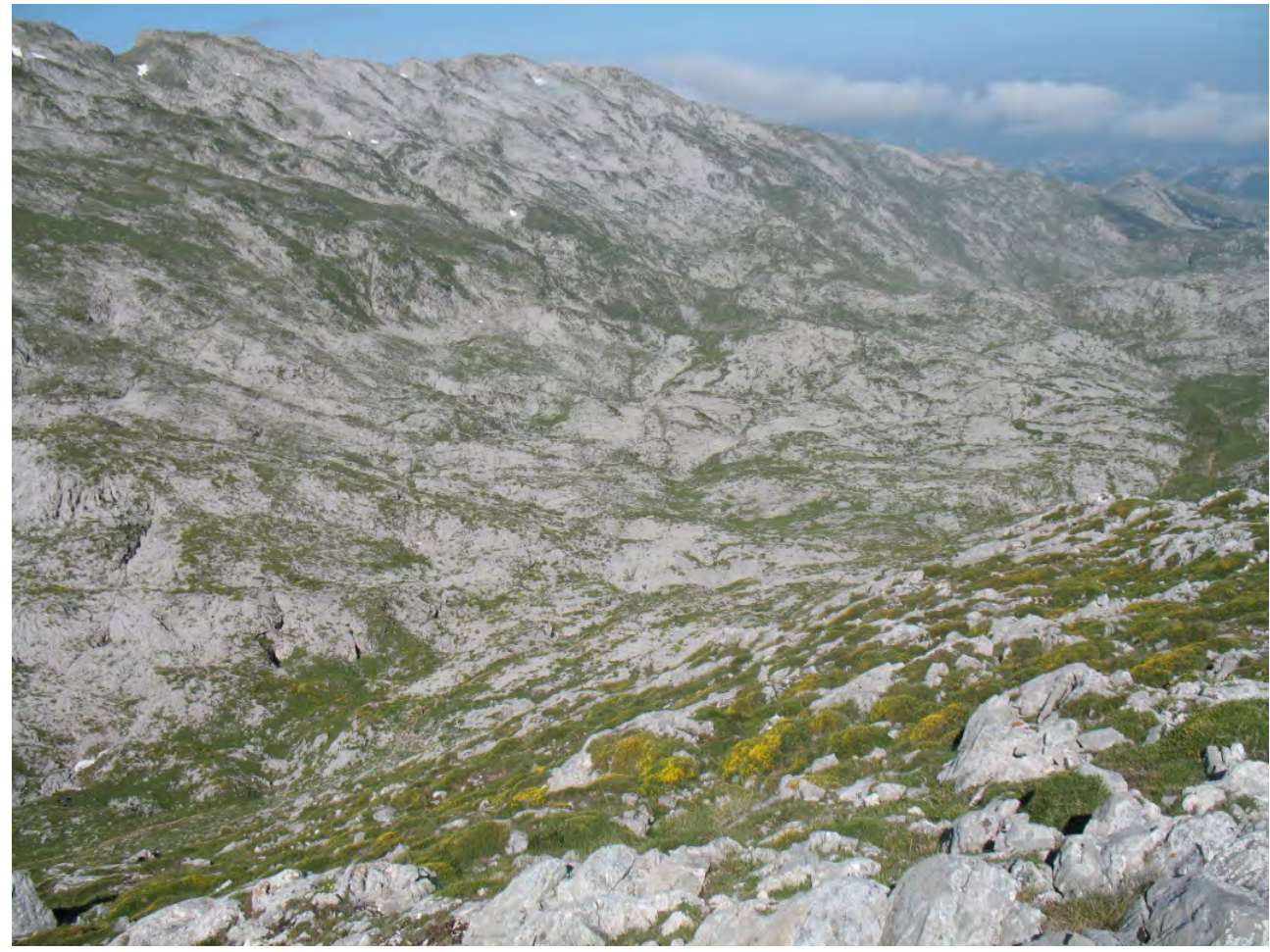

Fig. 24. Vista desde la Cabeza la Forma, en las inmediaciones de la Vega de Ario, hacia el área del Altu la Rasa. Se trata de un paisaje dominado casi en exclusiva por la infiltración de las escorrentías y la disolución de la caliza, que aflora en superficie de forma generalizada ante la exigüidad de los suelos y de la cobertura vegetal.
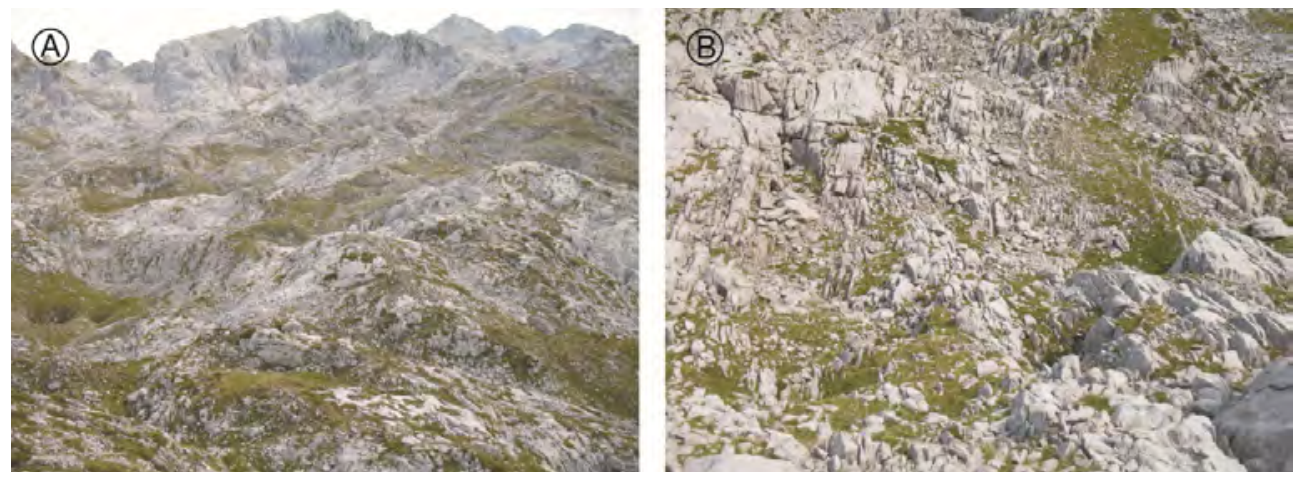

Fig. 25. (A) Vista general del desierto kárstico en los alrededores del H.ou del Agua con las cimas de las Torres de los Cabrones (2270 m), la Torre del Alba (2390 m), Peña Santa de Castilla (2596 m) y la Torre de la Canal Parda $(2350 \mathrm{~m})$ al fondo, y (B) detalle del desierto kárstico camino del H.ou del Agua a la Vega de Aliseda. Dolinas y lapiaces labrados a favor de un afloramiento verticalizado de calizas tableadas. 


\section{4. Área de karst nival de alta montaña}

La última franja kárstica diferenciada se ciñe a la alta montaña del Cornión, por encima de los $1700 \mathrm{~m}$ de altitud. Se trata de un área definida por la influencia nival, que se materializa en una rápida evolución de las formas kársticas (RUIZ-FERNÁNDEZ Y SERRANO, 2011). La ausencia de suelos y vegetación es prácticamente total. Tan sólo se han formado suelos incipientes sobre las morrenas depositadas a los pies de los grupos de cumbres más elevadas (RUIZ-FERNÁNDEZ Y GARCÍA-HERNÁNDEZ, 2018), así como sobre materiales finos generados por la meteorización de las dolomías y sobre sedimentos arcillosos que, en cualquier caso, ocupan muy poca extensión. Otra característica destacable es la presencia de neveros estacionales e incluso permanen- tes. Las aguas de fusión nival realizan una eficaz disolución kárstica en las inmediaciones de estos neveros, que se combina con la gelifracción. Siguiendo ciclos de duración diaria, humedecen la superficie de los afloramientos calcáreos, lo que genera una intensa corrosión kárstica que da lugar a la formación de numerosas oquedades, tabiques y rugosidades fácilmente atacables por la crioclastia (CASTAÑÓN Y FROCHOSO, 1998). Esta área coincide aproximadamente con el cinturón periglaciar del Macizo del Cornión, dentro del que a su vez se han diferenciado dos subpisos, el nivoperiglacial y el crionival, definidos por dinámicas geomorfológicas de diferente intensidad y por la existencia o no de determinados procesos como la crioturbación (SERRANO Y GONZÁLEZ-TRUEBA, 2004: RUIZFERNÁNDEZ et al., 2014).

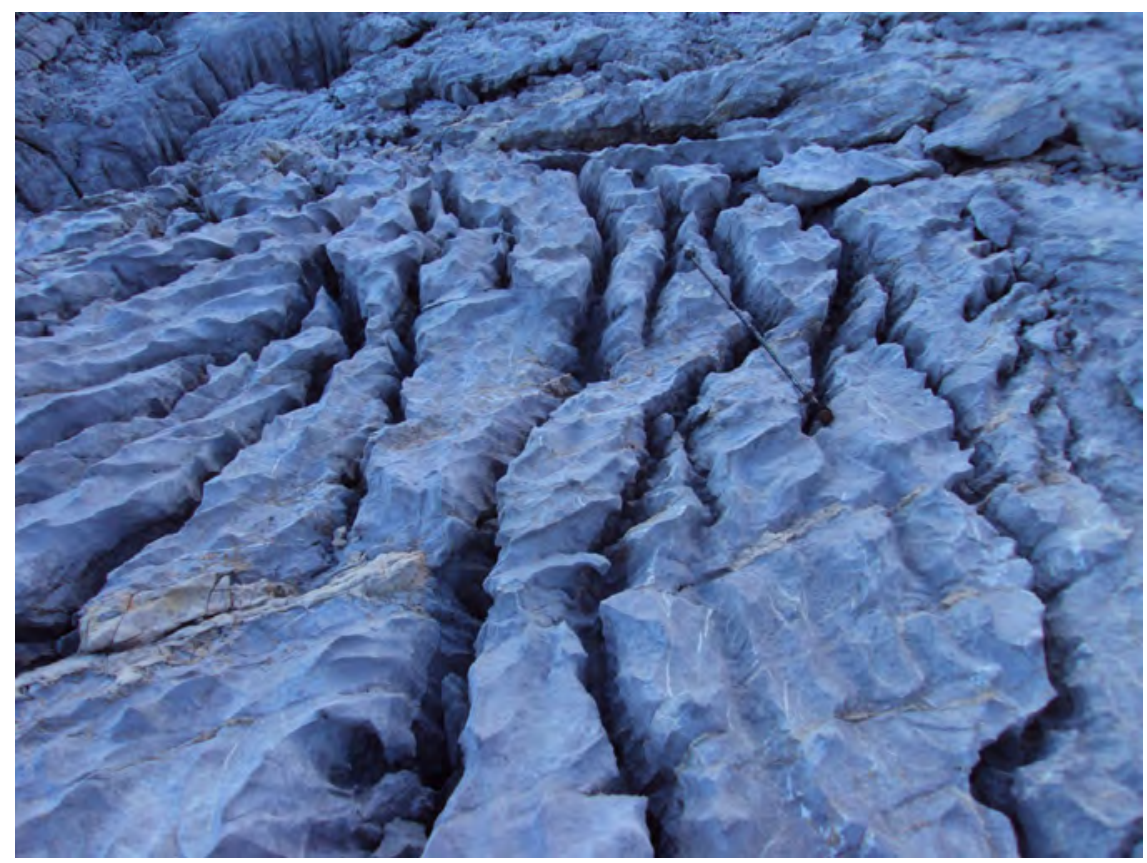

Fig. 26. Detalle de lapiaces nivales en La Llerona. 


\section{CONCLUSIONES}

El modelado kárstico del Macizo del Cornión se caracteriza por la existencia de una gran variedad de morfologías exokársticas y endokársticas, generadas por la disolución o bien debidas a la precipitación de los carbonatos. Una de sus principales características resulta de la interrelación entre el modelado kárstico y otros procesos, especialmente el glaciarismo cuaternario. Entre ambos tipos de modelado se han producido interferencias y relaciones de interdependencia. Por un lado, la existencia de un intrincado relieve kárstico previo, condicionó la dinámica glaciar. Por ello, el material morrénico que suele aparecer adosado a los umbrales o cubriendo el fondo de las depresiones glaciokársticas, no tiene por qué corresponderse con una respuesta climática, sino que en numerosas ocasiones se debe a cuestiones dinámicas relacionadas con la topografía extremadamente rugosa e intrincada característica del karst. Por otro lado, la expansión del hielo durante la Última Glaciación borró la morfología kárstica anterior, que solo se conservó en los ámbitos no glaciados. Los glaciares, a su vez, ejercieron una importante acción de abrasión y sobreexcavación sobre las depresiones kársticas preexistentes, dando lugar a grandes cubetas glaciokársticas. Además, en las áreas glaciadas el drenaje pasó a concentrarse en unas pocas cavidades, siendo difuso de nuevo con la retirada de los glaciares. Tras la deglaciación, las superficies trabajadas por la abrasión glaciar pasaron a ser karstificadas, desapareciendo casi por completo las huellas glaciares erosivas de detalle (estrías, acanaladuras), salvo en unos pocos sectores, principalmente aquellos cubiertos por glaciares durante la PEH, donde la karstificación aún no ha progresado debido al escaso tiempo transcurrido.
Actualmente, las condiciones morfoclimáticas de la alta montaña determinan la evolución del modelado kárstico, existiendo una importante interrelación entre el karst y la morfodinámica periglaciar. Las cuantiosas precipitaciones, las temperaturas frías y la abundancia de aguas de fusión nival, favorecen la disolución kárstica. Con frecuencia, la disolución se combina con la crioclastia, interactuando y beneficiándose ambos procesos de forma recíproca, especialmente en las áreas elevadas.

La morfología kárstica actual del Cornión es consecuencia de la sucesión temporal de distintas condiciones morfoclimáticas y de la consiguiente actuación de diversos agentes morfogenéticos, de modo que se pueden diferenciar tres grandes fases de evolución del karst. La etapa preglaciar, de la que persisten algunos testimonios exokársticos como el karst en pináculos de las minas de Buferrera, así como ciertas formas exokársticas mayores y morfologías endokársticas como algunos niveles de galerías fósiles colgadas a cientos de metros sobre el nivel freático actual. Una segunda etapa coincidente con la expansión glaciar, en la que los glaciares se adaptaron al relieve previo, retrabajándolo y concentrando el drenaje de las escorrentías y, por último, otra tercera de karstificación postglaciar desarrollada en el Holoceno y caracterizada por la existencia de un karst nival en los sectores de mayor altitud, y un karst cubierto de tipo templado oceánico en la media y baja montaña.

Por último, el relieve kárstico del Cornión está integrado por una amplia variedad de morfologías y procesos que presentan variaciones en función de la altitud (además de por los consabidos factores estructurales), de modo que podemos diferenciar 
cuatro franjas kársticas organizadas a tenor de dicho factor: i) área de karst cubierto oceánico de media montaña (no ocupada por el hielo durante la Última Glaciación; las morfologías kársticas previas no fueron borradas o remodeladas); ii) sector de los frentes glaciares y las cubetas glaciokársticas bajas, circunscrito al área de la máxima expansión de los glaciares cuaternarios; iii) desierto kárstico, situado entre 1400 y 1700 $\mathrm{m}$ y definido por el predominio casi absoluto de los procesos kársticos, así como por la práctica inexistencia de suelos y vegetación; y iv) área de karst nival de alta montaña (por encima de $1700 \mathrm{~m}$ ), que constituye un cinturón definido por la influencia nival en el que las formas kársticas evolucionan con mayor rapidez, la casi total ausencia de suelos y vegetación, y la conservación de neveros estacionales y permanentes.

\section{AGRADECIMIENTOS}

Este artículo ha sido financiado por el Ministerio de Economía, Industria y Competitividad del Gobierno de España (Ref. CTM2016-77878-P).

\section{REFERENCIAS BIBLIOGRÁFICAS}

ALONSO-OTERO, F., BULLÓN, T. (1976) Evolución kárstica del sector sureste de la serranía de Cuenca. Estudios Geográficos, 145, 465-478.

ALONSO-OTERO, F (1986) Karst externo: las Torcas de Cuenca. En: Atlas de Geomorfología, Martínez de Pisón, E., Tello, B., Eds., Alianza Editorial, Madrid, 273284.

ALONSO, F., GONZÁLEZ, J.A., UGARTE, F. (1987) Sur 1'evolution de Trois Grandes Depresiones Karstiques de la
Serranía de cuenca (España). Mediterranee, 1,21-32.

ALONSO, V. (1991) Geomorfología de las cabeceras de los ríos Narcea, Navia y Sil, $y$ del Parque Nacional de la Montaña de Covadonga ( NO de la Península Ibérica). Tesis Doctoral (inédita), Departamento de Geología de la Universidad de Oviedo, Oviedo, 366 p.

ARENAS, C., GUTIÉRREZ, F., OSÁCAR, C., SANCHO, C. (2000) Sedimentology and geochimistry of fluviolacustrine tufa deposits controlled by evaporite solution subsidence in the central Ebro, NE Spain. Sedimentology, 47, 883-909.

AUTENSACH, H. (1964) Die Iberische Halbinsel. Geographische Handbücher, Munich, $700 \mathrm{p}$.

BAENA, R., RECIO, J.M., DÍAZ DEL OLMO, F. (1993) Paleokarst del sector Santa María de Trassierra-Las Ermitas (Sierra Morena, Córdoba), Cuaternario y Geomorfología, 7, 67-78.

BALLESTEROS, D., JIMÉNEZ, M., GARCÍA, J., GIRALT, S. (2011) Geological methods applied to speleogenetical research in vertical caves: the example of Torca Teyera shaft (Picos de Europa, northern Spain). Carbonates and Evaporites, 26 (1), 29-40.

BRUSI, D., PALLÍ, L., TRILLA, J. (1997) Modelo deposicional de las formaciones travertínicas de la depresión de Banyoles (Girona). Études de Géographie Physique, 26, 143-145.

BULLÓN-MATA, T (1986) Karst externo: la hoz de Beteta. En: Atlas de Geomorfología, Martínez de Pisón, E., Tello, B. Eds., Alianza Editorial, Madrid, 265-272.

CARRASCO, F. (2002) Karst y medio ambiente. Perspectiva desde Andalucía. En: 
Karst and Environment. Carrasco, F., Durán, J.J., Andreo, B. Eds., Fundación Cueva de Nerja, Madrid, 19-29.

CASTAÑÓN, J.C. (1989) Las formas de relieve de origen glaciar en los sectores central y oriental del Macizo Asturiano. Universidad de Oviedo, Oviedo, 788 p. (microfichas).

CASTAÑÓN, J.C., FROCHOSO, M. (1994) El periglaciarismo de la Cordillera Cantábrica. En: Periglaciarismo en la Península Ibérica, Canarias y Baleares. Monografías de la Sociedad Española de Geomorfología, $n^{o}$ 7, Gómez-Ortiz, A., Simón, M., Salvador, F., Eds., Servicio de Publicaciones de la Universidad de Granada, Granada, 75-91.

CASTAÑÓN, J.C., FROCHOSO, M. (1998) La alta Montaña Cantábrica: condiciones térmicas y morfodinámicas en los Picos de Europa. En: Procesos biofísicos actuales en medios fríos, Gómez-Ortiz, A., Salvador, F., Schulte, L., García, A., Eds., Universidad de Barcelona, Barcelona, 113-132.

COLLIGNON, B. (1985) Quelques éléments de géologie et d'hydrogéologie. Spelunca, 19, 7-12.

CORBEL, J. (1959) Érosion en terrain calcaire. Annales de Géographie, 366, 97120.

CRUZ, J. (1981) Evolución geomorfológica e hidrogeológica reciente del sector Tebar-Cañete la Real (Málaga) a la luz de la datación de formaciones travertínicas. Boletín Geológico y Minero, 92(4), 297-308.

CURRAS, A., ZAMORA, L., REDD, J.M., GARCÍA SOTO, E. FERRERO, S., ARMENGO, X., MEZQUINA, F., MARQUÉS, M.A., RIERA, S., JULIÁ, R. (2012) Climate change and human impact in central Spain during Roman times: High-resolution multi-proxy of a tuffa lake record (Somolinos, 1280 m.a.s.1), Catena, 89, 31-55

CVIJIC, J. (1893) Das karstphänomen. Geographische Abhandlungen, 5, 218-329.

DELANNOY, J.J., DÍAZ DEL OLMO, F., PULIDO, A. (1989) Karst du Massif de Cabra (Subbetique externe) et travertine de Priego (Sierra Horconera, Subbetique Moyen, Córdoba). En: Reunion FrancoEspagnol sur les Karsts méditerrannées d'Andalousie occidentale. Livret-Guide. Deleenoy, F., Díaz del Olmo, F., Pulido, A. Eds., Universidad de Sevilla, Sevilla, 29-62.

DELANNOY, J.J. (1999) Contribución al conocimiento de los macizos kársticos de las Serranías de Grazalema y de Ronda. En: Karst en Andalucía, Durán, J.J., López-Martínez, J. Eds., ITGE, Madrid, 93-129.

DÍAZ DEL OLMO, F. (1994) Travertines mediterranèes à la fin du Quaternaire: la sequence de Priego de Córdoba (Andalouise, Espagne), Speleochronos, 6, 23-30.

DÍAZ DEL OLMO, F., BAENA, R., ÁlVAREZ, G. (1994) Karst y Paleokarst de Sierra Morena (Sector Ossa Morena, Hespérico meridional). Espeleotemas, 4, 15-24.

DURÁN, J.J. (1996) Los sistemas kársticos de la provincia de Málaga y su evolución: contribución al conocimiento paleoclimático del Cuaternario en el Mediterráneo occidental. Tesis Doctoral (inédita), Universidad Complutense de Madrid, Madrid, 409 p.

FARIAS, P. (1982) La estructura del Sector Central de los Picos de Europa. Trabajos de Geología, 12, 63-72. 
FARIAS, P., JIMÉNEZ, M., MARQUÍNEZ, J. (1996) Nuevos datos sobre la estratigrafía del relleno cuaternario de la depresión de Comeya (Picos de Europa, Asturias). Geogaceta, 20 (5), 1116-1119.

FERNÁNDEZ, A., GONZÁLEZ, J.A., GARCÍA DEL CURA, M ${ }^{\mathrm{a}}$.A., ORDÓÑEZ, S. (1996) Edificios tobáceos actuales en el cauce del río Júcar (provincia de Albacete). Geogaceta, 20, 281284.

FERNÁNDEZ, A., GARCÍA DEL CURA, $M^{a}$.A., GONZÁLEZ, J.A., ORDÓÑEZ, S. (1998) Fluvial tuffas in the Jucar river valley. En: Actas XV International Sedimentological Congress. Universidad de Alicante, Alicante, (2) 134-139.

FERNÁNDEZ, A. (2000) La Sierra de Alcaraz y el Calar del Mundo. En: Guía de Castilla-La Mancha, González, J.A., Vázquez, A., Eds., Servicio de Publicaciones de Junta de Comunidades de Castilla-La Mancha, Toledo, 631-665.

FERNÁNDEZ, A. (2000) Intervención antrópica en el valle del Júcar: cambios en la morfodinámica y modificaciones en las acumulaciones tobáceas actuales. Geotemas, 1 (3), 105-111.

FERNÁNDEZ, A., RUIZ-FERNÁNDEZ, J., GALLINAR, D., GARCÍAHERNÁNDEZ, C. (2015) El patrimonio geológico de las hoces del Júcar (La Manchuela-Albacete): Una propuesta de lugar de interés geológico (LIG). En: Patrimonio geológico y geoparques, avances de un camino para todos. Hilario, A., Mendia, M., Monge-Ganuzas, E., Fernández, J., Belmonte, A., Eds, IGME, Madrid, 55-60.

FORD, D., WILLIAMS, P. (1989) Karst geomorphology and hydrology. Unwin Hyman, Londres, 601 p.
FROCHOSO, M., CASTAÑÓN, J.C. (1998) El relieve glaciar de la Cordillera Cantábrica. En: Las huellas glaciares de las montañas españolas, Gómez-Ortiz, A., Pérez-Alberti, A., Eds., Universidad de Santiago de Compostela, Santiago de Compostela, 65-137.

Gale, S.J., Hoare, P.G. (1997) The glacial history of the northwest Picos de Europa of northern Spain. Zeitschrift für Geomorphologie N. F., 41, 81-96.

GARCÍA-CODRÓN, J.C. (1989) La influencia del clima. En: El karst en España, Durán, J.J., López-Martínez, J., Eds., Monografías de la Sociedad Española de Geomorfología, no 4, SEG, Madrid, 73-82.

GARCÍA DEL CURA, M ${ }^{\mathrm{a}}$. A., GONZÁlEZ, J.A., ORDÓÑEZ, S. (1996) El sistema de represas tobáceas poco evolucionadas del río Arquillo (Alcaraz-Albacete). Cuadernos Geología Ibérica, 22, 321-332.

GONZÁlEZ, J.A., ORDÓÑEZ, S., GARCÍA DEL CURA, Ma.A. (1987) Evolución geomorfológica de las Lagunas de Ruidera (Albacete-Ciudad Real). Estudios geológicos, 43, 227-239.

GONZÁLEZ, J.A., ORDÓÑEZ, S., FERNÁNDEZ, A., GARCÍA DEL CURA, $M^{\text {a }}$.A. (2000) Acumulaciones tobáceas holocenas en la Sierra de Alcaraz (Albacete, España). Geotemas 1(3), 369-373.

GONZÁLEZ, J.A., RUBIO, V. (2000) Las transformaciones antrópicas del paisaje de los sistemas fluviales tobáceos del Centro de España. Boletín de la Real Sociedad Española de Historia Natural (Secc. Geol.), 96 (1-2), 369-373.

GONZÁLEZ, J.A., GARCÍA DEL CURA, Ma.A., ORDÓÑEZ, S. (2014) Las acu- 
mulaciones tobáceas en la Alcarria y áreas Ibéricas adyacentes. En: Las tobas en España, González, J.A, GonzálezAmuchastegui, M ${ }^{\text {a } . J ., ~ E d s ., ~ S o c i e d a d ~}$ Española de Geomorfología, Madrid, 207-218.

GONZÁlEZ, J.A, FIDALGO, C., ARTEAGA, C., GONZÁLEZ-AMUCHASTEGUI, M ${ }^{\mathrm{a} . J}$., RUBIO, V. (2014) La degradación antrópica de los paisajes tobáceos. En: Las tobas en España, González, J.A, González-Amuchastegui, $M^{a}$.J., Eds., Sociedad Española de Geomorfología, Madrid, 317-338.

GONZÁLEZ-AMUCHASTEGUI, M ${ }^{\mathrm{a}}$.J., GONZÁLEZ, J.A. (1993) Significado geomorfológico de las acumulaciones tobáceas del alto valle del río Tajo (sector Peñalén-Huertapelayo). En: El Cuaternario de España y Portugal. ITGM Eds. Ministerio de Ciencia y Tecnología, Madrid, 99-109.

GONZÁLEZ-AMUCHASTEGUI, Ma .J. (1998) Geomorfología y etapas de karstificación en la Rama Castellana del sistema Ibérico. Estudios Geográficos, 232, 111-125.

GONZÁLEZ-AMUCHASTEGUI, M ${ }^{\mathrm{a}}$.J., SERRANO, E. (2007) Evolución geomorfológica, cambios ambientales e intervención humana durante el Holoceno en la cuenca alta del Ebro: las tobas de los valles del Purón y Molinar. Estudios Geográficos, 263, 527-546.

GONZÁLEZ-AMUCHASTEGUI, M ${ }^{\mathrm{a}}$.J., SERRANO, E. (2013) Acumulaciones tobáceas y evolución del paisaje: cronología y fases morfogenéticas en el Alto Ebro (Burgos). Cuaternario y Geomorfología, 27 (1-2), 9-32.

GONZÁLEZ-TRUEBA, J.J. (2007a) Geomorfología del Macizo Central del Parque
Nacional Picos de Europa. OAPN, Ministerio de Medio Ambiente, Madrid, 231 p.

GONZÁLEZ-TRUEBA, J.J. (2007b) La Pequeña Edad del Hielo en los Picos de Europa. Servicio de Publicaciones de la Universidad de Cantabria - Fundación Marcelino Botín, Santander, 186 p.

GONZÁlEZ-TRUEBA, J.J., SERRANO, E. (2010) La nieve en los Picos de Europa. Cuadernos de Investigación Geográfica, 36 (2), 61-84.

GRACIA, F.J, CUCHÍ, J.A. (1993) Control tectónico de los travertinos fluviales del río Jiloca (Cordillera Ibérica Central) En: El Cuaternario de España y Portugal. ITGM Eds. Ministerio de Ciencia y Tecnología, Madrid, 697-706.

HOYOS, M. (1979) El karst en Asturias en el Pleistoceno Superior y Holoceno. Tesis Doctoral (inédita), Universidad Complutense de Madrid, Madrid, $413 \mathrm{p}$.

HOYOS, M., HERRERO, N. (1989) El karst en la Cornisa Cantábrica. En: El karst en España, Durán, J.J., López-Martínez, J., Eds., Monografías de la Sociedad Española de Geomorfología, n ${ }^{\circ}$ 4, SEG, Madrid, 109-120.

JULIÁN, A. (1994) El karst del pico del Castillo de Acher (Pirineo Occidental, Huesca). Factores condicionantes de su distribución espacial. Geographicalia, 31, 127-141.

JULIÁN, A., CHUECA, J. (1999) Cartografía de zonas probables de aludes en el valle de Ordesa (Pirineo Aragonés). Geographicalia, 37, 73-86.

LAVERTY, M., SENIOR, K.J. (1981) Geology of the Ario Region and cave development in Pozu del Xitu. Proceedings of the Oxford University Cave Club, 10, 41-50. 
LOISELEUR, B., SALVAYRE, H. (1978) Sur quelques aspects de la morphologie superficielle du karst alpin de la Charetalp. Revue de Geographie Alpine, LXVI, 167-172.

LÓPEZ BERMÚDEZ, F. (1974) El karst del Calar del Mundo (Albacete). Estudios Geográficos, 136, 359-404.

LÓPEZ-FERNÁNDEZ, A. (2007) Los travertinos de Santa María de Trassiera (Córdoba, España), Boletín de la Real Academia de Córdoba, de Ciencias, Bellas Letras y Nobles Artes, 152, 81-94

LÓPEZ-MARTÍNEZ, J. (1984) Disolución de rocas carbonatadas. Cuantificación del proceso actual de karstificación en el Macizo de la Piedra de San Martin (Pirineo Occidental), Cuadernos de Investigación Geográfica, 10, 127-138.

MAIRE, R. (1990) La haute montagne calcaire. Karsts, cavités, remplissages, Quaternaire, paléoclimats. KarstologiaMémories, 3, Association Française de karstologie y Fédération Française de Spéléologie, La Ravoire, 731 p.

MARQUÍNEZ, J. (1978) Estudio geológico del sector SE de los Picos de Europa (Cordillera Cantábrica, NO de España). Trabajos de Geología, 10, 295-315.

MARQUÍNEZ, J. (1989) Mapa geológico de la Región del Cuera y los Picos de Europa. Trabajos de Geología, 18, 137-144.

MIOTKE, F.D. (1968) Karstmorphologische studien in der glazial-überformten Höhenstufe der Picos de Europa, Nordspanien. Selbtverlag der Geografischen Gessellschaft, Hannover, $161 \mathrm{p}$.

MUÑOZ, J. (1982) Geografía Física. El relieve, el clima y las aguas. En: Geografía de Asturias. Tomo I, Quirós, F., Dir., Ayalga Ediciones, Salinas, 1-271.

NICOD, J. (1972) Pays et paysages du cal- caire. Presses Universitaires de France, París, 244 p.

NICOD, J. (1975) Les cuvettes glaciokarstiques dans les hautes montagnes mediterraneennes et alpines. Cuadernos Geográficos de la Universidad de Granada, Serie Monográfica, 1, 7-17.

NICOD, J. (1976) Les Dolomites de la Brenta (Italie), karst haut-alpin typique et le problème des cuvettes glacio-karstiques. Zeitschrift für Geomorphologie N. F., 26, 35-57.

NICOD, J., AMBERT, P., AMBERT, M., FABRE, G., GUENDON, J. L., MAZET, M., OLLIÉ, C., ORENGO, C. (1978) Phenomenes glacio-karstiques et nivo-karstiques sur la carte geomorphologique du Devoluy Meridional, Plateaux de Bure et d'Aurouze. Revue de Geographie Alpine, LXVI, 149-165.

PARDO-IGÚZQUIZA, E., DURÁN, J.J., ROBLEDO-ARDILA, P.A. (2016) Modelo fractal de la distribución del tamaño de las dolinas en el macizo kárstico de la Sierra de las Nieves (Málaga, España). Cuaternario y Geomorfología, 30 (1-2), 61-73.

PORRAS, A.I. (2000) Chronostratigraphy at constantine: a Holocene travertine in Sierra Norte (Sevilla, Spain) En: Environmental changes during the Holocene, Díaz del Olmo, F., Faust, D., Porras, A.I., Eds., Meeting INQUA, Sevilla, 179-180.

ROSSI, C. (2004) Picos de Europa, Spain. En: Encyclopaedia of Caves and Karst Science, Gunn, J., Ed., Fitzroy Dearborn, New York-London, 582-585.

RUIZ-FERNÁNDEZ, J. (2015) Las formas de modelado glaciar, periglaciar y fluviotorrencial del Macizo Occidental de los Picos de Europa (Cordillera Cantá- 
brica). Boletín de la Asociación de Geógrafos Españoles, 68, 581-587.

RUIZ-FERNANDEZ, J., GARCÍAHERNÁNDEZ, C. (2018) Morfología y evolución glaciar en el Macizo del Cornión (Picos de Europa, Montañas Cantábricas). Cadernos do Laboratorio Xeolóxico de Laxe, 40, 29-68.

RUIZ-FERNANDEZ, J., OLIVA, M., CRUCES, A., LOPES, V., FREITAS, M.C., ANDRADE, C., GARCIAHERNANDEZ, C., LOPEZ-SAEZ, J.A., GERALDES, M. (2016) Environmental evolution in the Picos de Europa (Cantabrian Mountains, SW Europe) since the Last Glaciation. Quaternary Science Reviews, 138, 87-104.

RUIZ-FERNÁNDEZ， J., OLIVA, M., HRBÁ冈EK, F., VIEIRA, G., GARCÍAHERNÁNDEZ, C. (2017) Soil temperatures in an Atlantic high mountain environment: The Forcadona buried ice patch (Picos de Europa, NW Spain). Catena, 149 (2), 637-647.

RUIZ-FERNÁNDEZ, J., POBLETE PIEDRABUENA, M.A. (2012) Las simas del macizo occidental de los Picos de Europa: disposición estructural, depósitos asociados y características del drenaje. Investigaciones Geográficas, 57, 205-223. RUIZ-FERNÁNDEZ, J., POBLETE, M.A., GARCÍA, C. (2014) Características morfoclimáticas y procesos y formas periglaciares actuales en el Macizo Occidental de los Picos de Europa (Cordillera Cantábrica). En: Avances, métodos y técnicas en el estudio del periglaciarismo, Gómez-Ortiz A., Salvador F., Oliva M., Salvà, M., Eds., Universidad de Barcelona, Barcelona, 91-103.

RUIZ-FERNÁNDEZ, J., SERRANO, E. (2011) El modelado kárstico en el Ma- cizo del Cornión. En: Geomorfología del Macizo Occidental del Parque Nacional Picos de Europa, González-Trueba, J.J. y Serrano, E., Eds., OAPN, Ministerio de Medio Ambiente, Madrid, 109-142.

SANCHO, C. PEÑA, J.L., MELÉNDEZ, A. (1997) Controls on Holocene an present day travertine formation in the Guadalaviar River (Iberian Chain, NE Spain). Zeitschrift für Geomorphologie,41, 289-307.

SANTOS, R., MARQUÍNEZ, J. (2005) Las formas del lapiaz en el sector norte del Macizo del Cornión, Picos de Europa. Cuaternario y Geomorfología, 19, 35-47.

SENIOR, K.J. (1987) Geology and speleogenesis of the M2 Cave System, Western Massif, Picos de Europa, Northern Spain. Cave Science, 14 (3), 93-103.

SERRANO, E., GONZÁLEZ-TRUEBA, J.J. (2004) Morfodinámica periglaciar en el grupo Peña Vieja (Macizo Central de los Picos de Europa - Cantabria). Cuaternario y Geomorfología, 18 (3-4), 73-88.

SERRANO, E., GONZÁLEZ-TRUEBA, J.J., PELLITERO, R., GONZÁLEZGARCÍA, M. Y GÓMEZ-LENDE, M. (2013) Quaternary glacial evolution in the Cantabrian Mountains (Northern Spain). Geomorphology, 196, 65-82.

SMART, P.L. (1984) The geology, geomorphology and speleogenesis of the Eastern Massif, Picos de Europa, Spain. Cave Science, 11 (4), 238-245.

SMART, P.L. (1986) Origin and development of glacio-karst closed depressions in the Picos de Europa, Spain. Zeitschrift für Geomorphologie N. F., 30, 423-443.

SWEETING, M.M. (1972) Karst landforms. McMilan Press, Londres, 362 p.

UGARTE, F., UGALDE, T. (1985) Le dinamique karstique actuelle a Aralar 
- Mendi (Moyenne Montagne Basco

- Cantabrique). Annales de la Société Géologique de Belgique, 108, 221-224.

VÁZQUEZ, M., PARDO, G., ARENAS, C., SANCHO, C. (2011) Fluvial diffluence episodes reflected in the Pleistocene tufa deposits of the river Piedra (Iberian rango, NE Spain). Geomorphology, 125, 1-10.

VÁZQUEZ, M., ARENAS, C., PARDO, G. (2013) A sedimentary facies model for stepped, fluvial tufa systems in the Iberian Range (Spain): the Quaternary Piedra and Mesa valleys used for uranium and thorium isotope determiantios. Sedimentology, 59 (2), 502-526.

VERHEYDEN, S., FAVERJON, M., BORCHERS, N., CHARAVEL R.,
CHOLIN, A., SÁNCHEZ, N., SCIPIONI, M., GILLET, R. Y DELABY S. (2007) La sima Thesaurus Fragilis. Exploraciones 2006 y 2007. Vega Huerta, macizo de Cornión, Picos de Europa. Subterránea, 28, 24-31.

VICENS, D., FORNÓS, J.J, RODRÍGUEZ-PEREA, A. (2014) Acumulaciones tobáceas en las Islas Baleares. Algunos ejemplos en la Isla de Mallorca. En: Las tobas en España, González, J.A, González-Amuchastegui, $\mathrm{M}^{\mathrm{a}}$.J., Eds., Sociedad Española de Geomorfología, Madrid, 303-314.

WHITE, W.B. (1988) Geomorphology and hydrology of karst terrains, Oxford University Press, New York - Oxford, 464 p. 